Research Article

\title{
Field Observation and Theoretical Study on an Existing Tunnel Underpassed by New Twin Tunnels
}

\author{
Qiongfang Zhang $\mathbb{D}^{1,2}$ \\ ${ }^{1}$ MOE Key Laboratory of Soft Soils and Geoenvironmental Engineering, Zhejiang University, Hangzhou 310058, China \\ ${ }^{2}$ Research Center of Coastal and Urban Geotechnical Engineering, Zhejiang University, Hangzhou 310058, China \\ Correspondence should be addressed to Qiongfang Zhang; yangziduozi@sina.com
}

Received 10 August 2017; Accepted 16 November 2017; Published 20 March 2018

Academic Editor: Andrea Benedetto

Copyright (c) 2018 Qiongfang Zhang. This is an open access article distributed under the Creative Commons Attribution License, which permits unrestricted use, distribution, and reproduction in any medium, provided the original work is properly cited.

The methodology of the existing displacement control is illustrated taking the shield of twin tunnels of Line 4 underpassing the upline tunnel of existing metro Line 1, for example. Vertical, horizontal, and convergence displacement of the existing tunnel is monitored and analyzed in detail in this paper. Shield parameters are predefined and adjusted based on the feedback of the displacement of Line 1. Short-term displacement of the existing tunnel is greatly influenced by the relative distance between the shield face and the existing tunnel and shield parameters. The shapes of horizontal and convergence displacement curves are similar. Line 1 is reinforced, and a new analysis method is firstly proposed for the design of reinforcement of the existing tunnel which is verified by the analytical methods derived from prior studies. The results show that the change of reinforcement stiffness has a greater effect on the normalized bending moment and the normalized shear force of the existing tunnel, and reinforcement of 25 rings on either side of the intersection point is the best choice in this case. The proposed model can be widely applicable for reinforcement design and safety check of the existing tunnel.

\section{Introduction}

The interaction between new shield construction and existing tunnel has become a common and important issue with the rapid development of underground traffic system, which has been studied in the past using a variety of approaches: field observations, model tests, analytical methods, and finite element modeling. Kim and Liu et al. [1, 2] presented a good summary comparison of the studies and only studies that illustrates the shield underpassing or parallel underpassing the existing tunnel. Yamaguchi et al. [3] presented successively the numerical model and then analyzed three configurations of the twin tunnels in Japan: aligned horizontally, vertically, and inclined. The construction of the upper tunnel at first leads to both higher settlement and bending moment. The maximum soil settlement was obtained for vertical-aligned tunnels, while horizontal-aligned tunnels caused the lowest settlement. Addenbrooke and Potts [4] analyzed the influence of tunnel position, tunnel spacing, rest period, and sequence of excavation on the interaction between the two tunnels.
It concentrated on the shape of the settlement profile and the volume loss induced by the two tunnels. The shield underpassing the existing tunnel is highly site specific. The soil condition, the tunnel buried depth, and the relative position of the new tunnel and existing tunnel all affect the response of the existing tunnel. Field observations remain the commonly recognized approach for understanding the interaction behavior between the new tunnel and existing tunnel. Usually, the underpassing of a shield with a loss of soil often causes settlement of the existing tunnel at last [5-7]. Chehade and Shahrour [8] used the finite element method to investigate the influence of the relative position of tunnels and the construction procedure on the soil settlement. The results showed that the settlements of the existing tunnel for the vertical parallel tunnels were larger than those for the horizontal parallel tunnels. Li and Yuan [9] studied the twin tunnels passing under a double-decked tunnel at an angle of 55 in weathered granite gneiss. Only settlements were found, and the horizontal displacement was smaller than the vertical displacement in the existing tunnel. Despite a number of studies 
having been carried out, current understanding of the interaction between the two tunnels is still limited.

In order to ensure the stability of the existing tunnel, local thickening is needed at the sides of the existing concrete lining. There are a plenty of research about the conventional reinforcement methods such as inner steel plate reinforcement or new reinforcement approaches such as FRC or composite concrete, but they all focus on the performance of reinforcement on the single ring. The effect of reinforcement on the longitudinal behavior of the tunnel is not yet clear in current analysis. The analytical method of longitudinal displacement of the tunnel due to adjacent excavation and multiple tunnelling is researched a lot: (1) the elastic continuum models developed by Vorster et al. [10], (2) the Winkler model [11], and (3) the two-parameter elastic models. When variable stiffness of the existing tunnel needs to be considered, the methods are no longer applicable. Selvadurai [12] divided the beam on foundation into $\mathrm{N}$ elements and used the method of initial parameters to analyze the beam's displacement. In the paper, we assume the existing tunnel as a beam resting on a two-parameter foundation, combining the initial parameter method and the transfer matrix method to analyze the reinforcement effect on the longitudinal behavior of the existing tunnel.

The major objectives of this paper are (1) to investigate the influence of the tunnel driving parameters and the relative distance between the shield and the existing tunnel on the existing tunnel based on the interpretation of the field measured data and (2) to study the effects of different stiffness and ranges of reinforcement on the existing tunnel using analytical methods.

\section{Project Overview}

The location of the Line 4 tunnels and the upline of Line 1 are shown in Figure 1. The upline of Line 1 is the existing tunnel built in 2012. Figure 2 shows a plan view of tunnel alignment and arrangement of the monitoring points in the existing tunnel. The shield of the northbound tunnel of Line 4 starts from Guanhe Station, passes under the existing tunnel with a small angle of $23^{\circ}$, and reaches East railway station at last. Then, the shield machine is reassembled with tunnels in a reversed direction. The northbound tunnel with a length of $329.675 \mathrm{~m}$ consists of 275 rings numbered starting with zero from Guanhe Station to East railway station, while the southbound tunnel with a length of $323.834 \mathrm{~m}$ consists of 270 rings numbered starting with zero from East railway station to Guanhe Station. The lateral distance between the northbound tunnel and the southbound tunnel is $9.4-15.0 \mathrm{~m}$.

Figure 3 shows the longitudinal profile of soil and tunnels. The vertical distance between the existing tunnel and Line 4 is $2.12 \mathrm{~m}$. The existing tunnel and new tunnels are all built using an articulated shield tunnelling machine with an outer diameter of $6.4 \mathrm{~m}$ and a length of $8.5 \mathrm{~m}$. The spokes plus panel-type cutter head are used, and the aperture ratio of cutter head is $40 \%$. Each ring of new tunnels consists of six precast concrete segments. The outer diameter, the inner diameter, and the thickness of the segment are $6.2 \mathrm{~m}, 5.5 \mathrm{~m}$, and $0.35 \mathrm{~m}$, respectively.
2.1. Soil Condition. The engineering properties of the rock and the soils in this site are very complicated. Figure 4 shows geotechnical parameters of soil in this site. The soil layers from top to bottom are (1) fill, (3) silty clay, (4) clay, (6) the muddy silty clay, and (8) soft silty clay and gravel layer. The existing tunnel and new tunnels are located in the muddy silty clay layer at a depth of $20 \mathrm{~m}$ and $25 \mathrm{~m}$, respectively. Along the metro line, an extensive geotechnical investigation is carried out. The standard penetration test (SPT), vane shear test (VST), piezocone test (CPTU), flat plate dilatometer test (DMT), and water pumping test (WPT) are conducted along Line 1 . The maximum water content of clay and muddy silty clay is about $40 \%$, which is close to the liquid limit value. The average undrained shear strength of undisturbed clay and remolded clay which is obtained by VST is $70.5 \mathrm{kPa}$ and $10.9 \mathrm{kPa}$, respectively. The coefficient of the at-rest earth pressure $\left(K_{0}\right)$ of soft clay is obtained by DMT.

2.2. Hydrological Geology. The shallow ground water is pore phreatic water, mainly found in layers from (1) to (8). The elevation of the water surface is $2.232 \mathrm{~m}$. The laboratory penetration test and field steady flow test can be seen in Table 1. It can be seen that the permeability coefficient of the clay layer is very small, and the permeability coefficient of the gravel layer is $1-2 \mathrm{~m} / \mathrm{d}$. The seepage induced from water head difference might influence the stability of tunnels.

\section{Shield Driving Parameters}

Figure 5 presents advance-time curve of the shield. Before underpassing the existing tunnel, the shield advances with a very slow rate. The tunnel advancing rate is 7-8 rings/day, and the penetration rate of the shield ranges from 20 to $25 \mathrm{~mm} \cdot \mathrm{min}^{-1}$.

Figure 6 shows the applied tunnel face pressure. In practice, the tunnel face pressure should be adjusted with the theoretical value as well as the feedback displacement of the existing tunnel. The existing tunnel redistributes the soil stress, and the applied tunnel face pressure should be adjusted by (1) as follows:

$$
p_{2}=K_{0} \gamma^{\prime} h+p_{w}+Q_{1}-Q_{2} \pm 20 \mathrm{kPa}
$$

where $K_{0}$ is the coefficient of earth pressure at rest; $\gamma^{\prime}$ is the effective gravity of soil; $h$ is the thickness of overburden depth $(\mathrm{m}) ; p_{w}$ is the water pressure; $Q_{1}$ is the weight of the existing tunnel $(\mathrm{kN}) ; Q_{2}$ is the weight of the soil with the same internal volume of the existing tunnel $(\mathrm{kN})$; and $20 \mathrm{kPa}$ is the pressure fluctuation.

The applied tunnel face pressure of the southbound tunnel cannot be calculated by (1) which is due to the redistribution of the earth pressure after the construction of the northbound tunnel nearby and should be adjusted according to the displacement of the existing tunnel.

Figure 7 shows the tail void grouting volume of the shield of the northbound and southbound tunnels of Line 4 . Shield parameter adjustments play an important role in the displacement controls, reducing the tail void grouting volume and applied tunnel face pressure when Line 1 heaves. Opposite measures are taken when there is a subsidence in Line 1. 


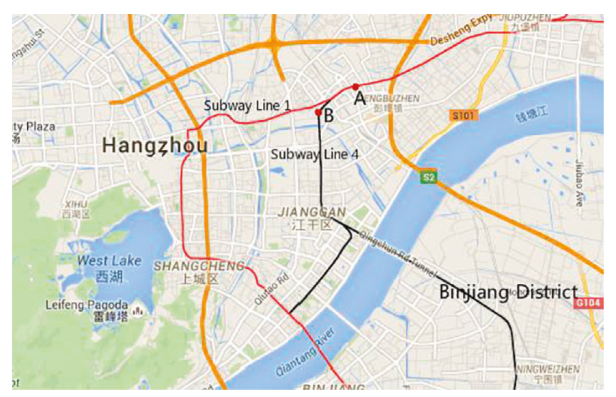

Figure 1: Location of the new tunnels and the existing tunnel in Hangzhou. A: Guanhe Station; B: East railway station.

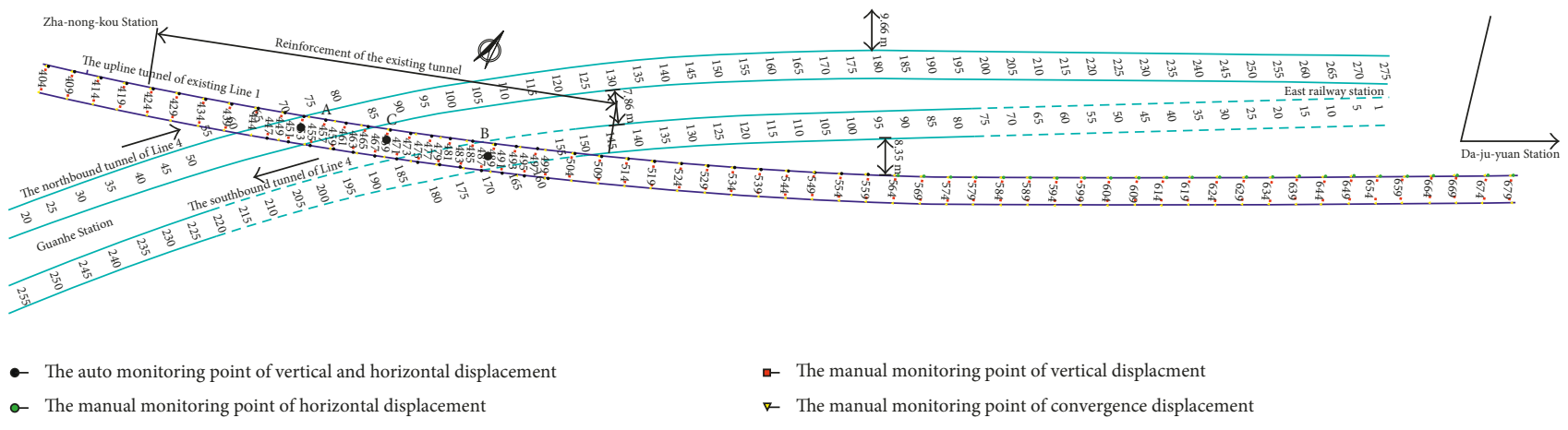

Figure 2: Plan view of tunnel alignment and location of the monitored rings.

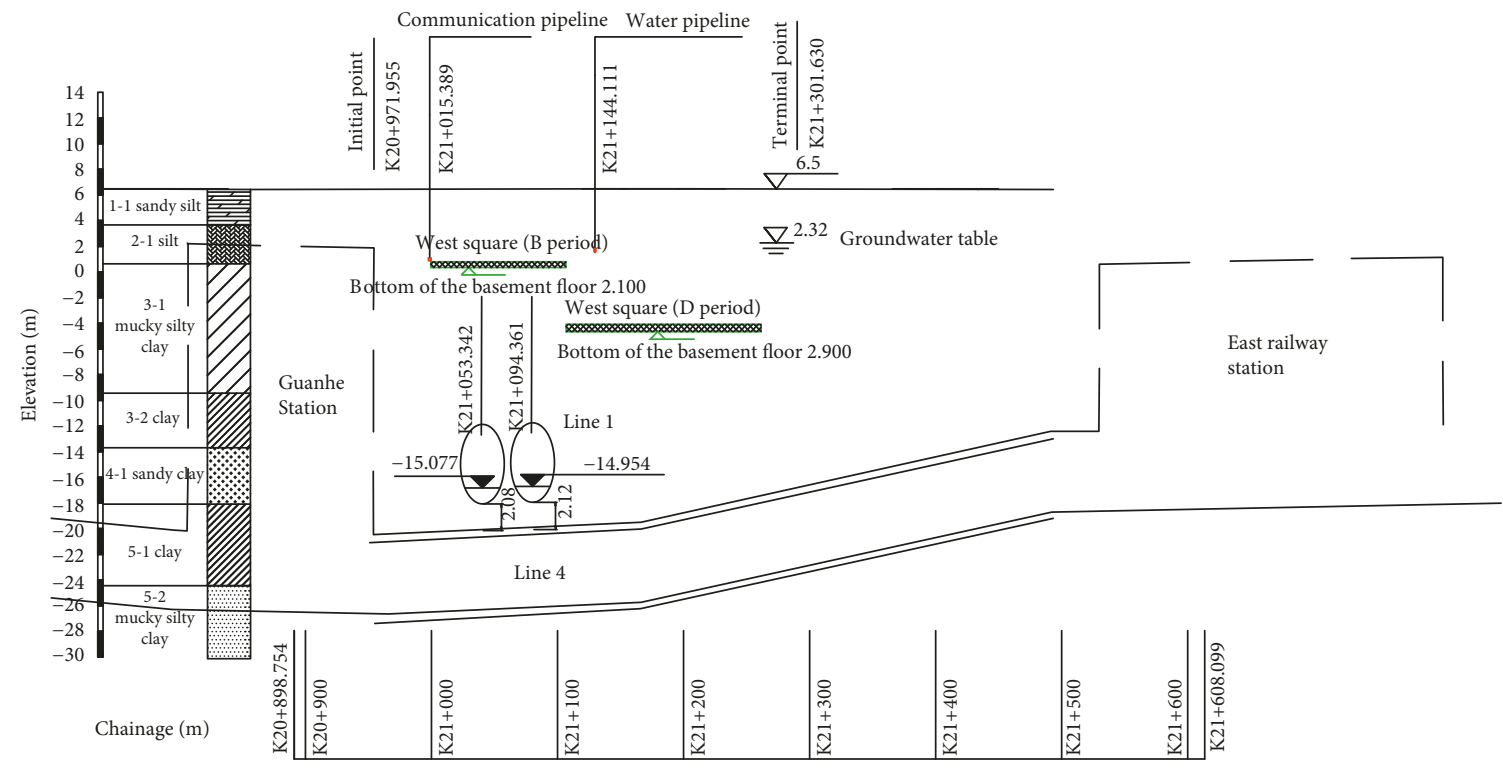

Figure 3: Longitudinal profile of soils and tunnels.

\section{Observation Results and Discussions}

4.1. Monitoring Arrangement of Line 1. Arrangement of the monitoring rings of the existing tunnel can be seen in Figure 2. The total station Topcon MS05AX fixed on the tunnel sidewall arranged from rings 404 to 559 in the existing tunnel is an automatic real-time measuring system which is used to monitor vertical and horizontal displacement. One monitor section is set every two rings in the most affected zone (from rings 447 to 499 in the existing tunnel), and one monitor section is set every five rings in the rest part. An LECAI D5 hand-held distance finder is used to monitor the converge displacement every 5 rings from 404 to 679 in the existing tunnel. The arrangement of monitoring points at the cross section of the existing tunnel is shown in Figure 8. 


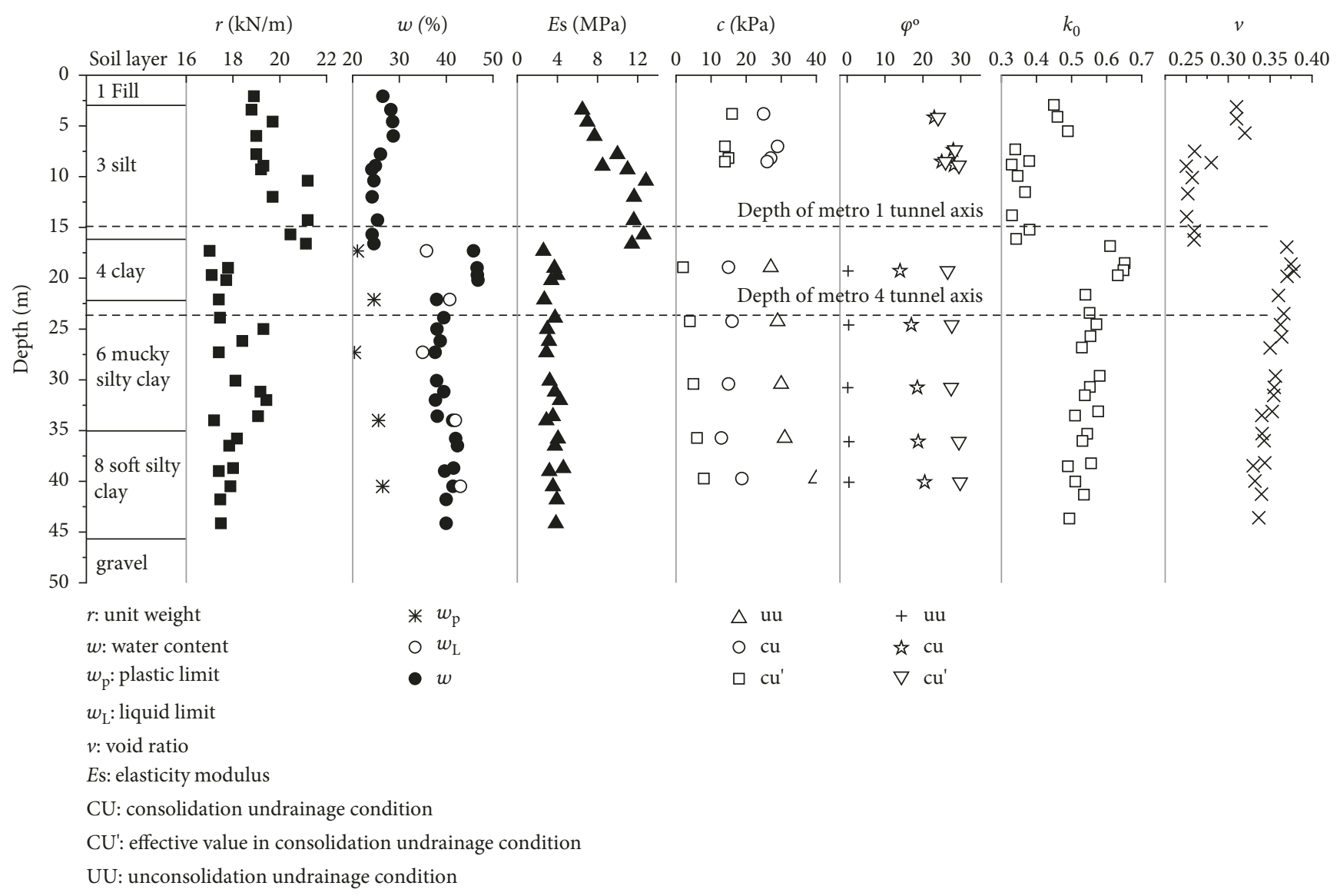

FIGURE 4: Soil profile and geotechnical parameters.

4.2. Displacement of the Existing Tunnel. The location of point A as shown in Figure 2 is corresponding to the intersection point of a plan view of the existing tunnel and northbound tunnel of Line 4 . The location of point $B$ is corresponding to the intersection point of the plan view of the existing tunnel and southbound tunnel of Line 4 . The middle point of points $\mathrm{A}$ and $\mathrm{B}$ is point $\mathrm{C}$.

4.2.1. Vertical Displacement of the Existing Tunnel. Figure 9 shows time-varying vertical displacement in the monitoring rings of the existing tunnel. The $x$-axis is the ring number of the existing tunnel. A positive value of the ordinate denotes heave, while a negative value denotes settlement of the existing tunnel. The selected monitoring rings start to heave when the shield face is $0-10 \mathrm{~m}$ away from the selected monitoring rings which is mainly due to large applied tunnel face pressure, bulk addictive thrust (Figure 6), and the friction force between the shield shell and soil mass. When the shield tail is far beyond the selected monitoring rings, a reduction of heave in the selected monitoring points is observed which is mainly due to the closure of the tail void. Only small settlements and heaves are measured after the construction of the northbound tunnel. During the 3-month shutdown of the shield, additional settlement ranges from $2 \mathrm{~mm}$ to $3 \mathrm{~mm}$ can be observed in rings from 430 to 520 . Additional settlements
TABLE 1: Laboratory penetration test and field steady flow test.

\begin{tabular}{lccc}
\hline & \multicolumn{2}{c}{ Laboratory } & \\
Soil layer & penetration test $(\mathrm{cm} / \mathrm{s})$ & Field steady flow test $(\mathrm{cm} / \mathrm{s})$ \\
& $K_{v}$ & $K_{h}$ & $K$ \\
\hline $3-2$ & $4.79 \times 10^{-5}$ & $7.81 \times 10^{-5}$ & $4.21 \times 10^{-3}$ \\
$3-3$ & $2.55 \times 10^{-4}$ & $2.30 \times 10^{-4}$ & $1.57 \times 10^{-3}$ \\
$3-5$ & $9.63 \times 10^{-5}$ & $1.74 \times 10^{-4}$ & - \\
$3-6$ & $3.29 \times 10^{-4}$ & $3.01 \times 10^{-4}$ & - \\
$4-3$ & $2.39 \times 10^{-7}$ & $7.84 \times 10^{-7}$ & $/$ \\
$6-1$ & $2.06 \times 10^{-7}$ & $3.03 \times 10^{-7}$ & - \\
$6-2$ & $2.62 \times 10^{-7}$ & $1.28 \times 10^{-7}$ & - \\
$8-1$ & $1.88 \times 10^{-7}$ & $5.11 \times 10^{-7}$ & - \\
\hline
\end{tabular}

ranges from 2 to $4 \mathrm{~mm}$ were measured in rings from 460 to 540 during the southbound tunnel's construction. The long-term additional settlements, monitored up to 140 days (from 2014/6/1 to 2014/10/19), range from 2 to $4 \mathrm{~mm}$ in rings from 460 to 510 . The settlements of rings from 430 to 520 range from $2 \mathrm{~mm}$ to $12 \mathrm{~mm}$, and the settlement curve of the upline of Line 1 is " $U$ " shaped after the long-term monitoring. The settlement curve is approximately symmetric about the dashed line $\mathrm{C}$ after the long-term monitoring. The maximum settlement is $12 \mathrm{~mm}$ which is located in ring 487. 


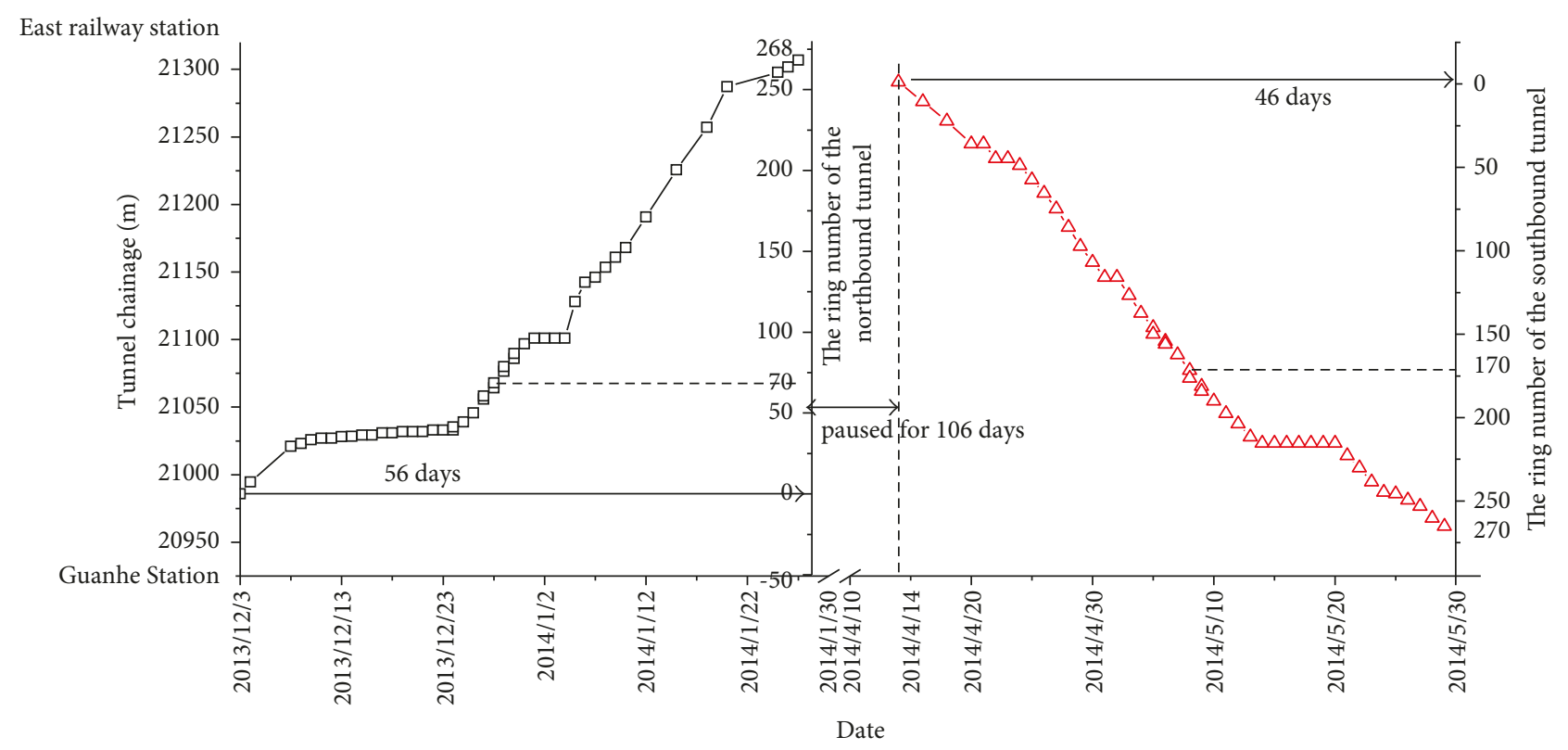

- - The tunnel face of the northbound tunnel

$-\Delta-$ The tunnel face of the southbound tunnel

Figure 5: Advance-time curve of the shield.

4.2.2. Horizontal Displacement of the Existing Tunnel. The horizontal displacement of the existing tunnel with respect to the location of the shield is illustrated in Figure 10. A positive horizontal displacement denotes northward transverse tunnel movement away from the original tunnel centerline, while a negative horizontal displacement denotes southward transverse tunnel movement away from the original tunnel centerline.

There are northward displacement on the left side of point $\mathrm{C}$ and southward displacement on the right side of point $\mathrm{C}$. The horizontal displacement curve is approximately symmetric about point $\mathrm{C}$ after the long-term monitoring. The maximum northward displacement is $10 \mathrm{~mm}$ in the ring near the intersection point $\mathrm{A}$, and the maximum southward displacement is $-10.5 \mathrm{~mm}$ in the ring near the intersection point B after the completion of the two tunnels' construction. During the construction of the northbound tunnel, rings from 453 to 471 move southward which is likely due to the additional bulkhead additive thrust and the squeezing force provided by the shield shell. When the shield tail leaves ring 459, rings from 439 to 459 move southward slowly. Only 2 to $5 \mathrm{~mm}$ additional southward displacement is measured in rings from 487 to 560, and nearly no displacement is observed on the left side of point B during the construction of the southbound tunnel which is mainly due to the northbound tunnel's barrier effect. No change of horizontal displacement is observed in the long-term conditions (from $2014 / 5 / 28$ to $2014 / 10 / 19$ ).

\subsubsection{Convergence Displacement of the Existing} Tunnel. Figure 11 shows the convergence displacement of the existing tunnel with respect to the locations of the shield.

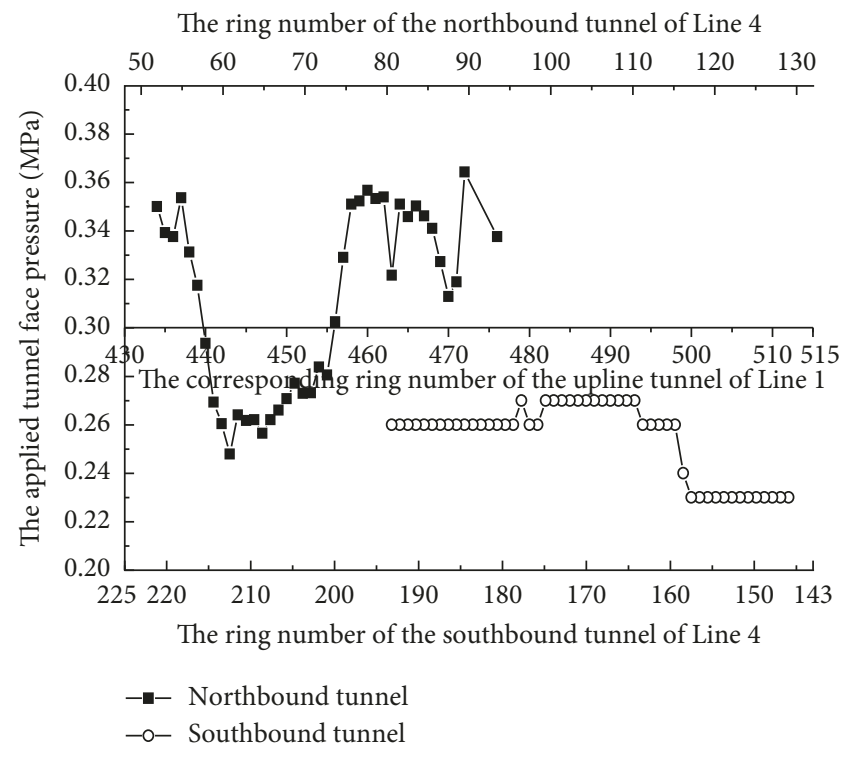

FIGURE 6: The applied tunnel face pressure.

A negative value indicates the reduction horizontal diameter of the existing tunnel, while a positive value indicates the addition horizontal diameter of the existing tunnel. It can be observed that the convergence displacement is not obvious when the shield reaches ring 48 (22 rings away from the intersection point A). During the process of the shield driving from ring 64 to ring 87, a significantly additional increase in the negative convergence displacement in rings from 440 to 490 is observed, and the maximum displacement occurs in the intersection point $\mathrm{A}$. The reason might be that the shield face squeezes one side of the existing tunnel, 


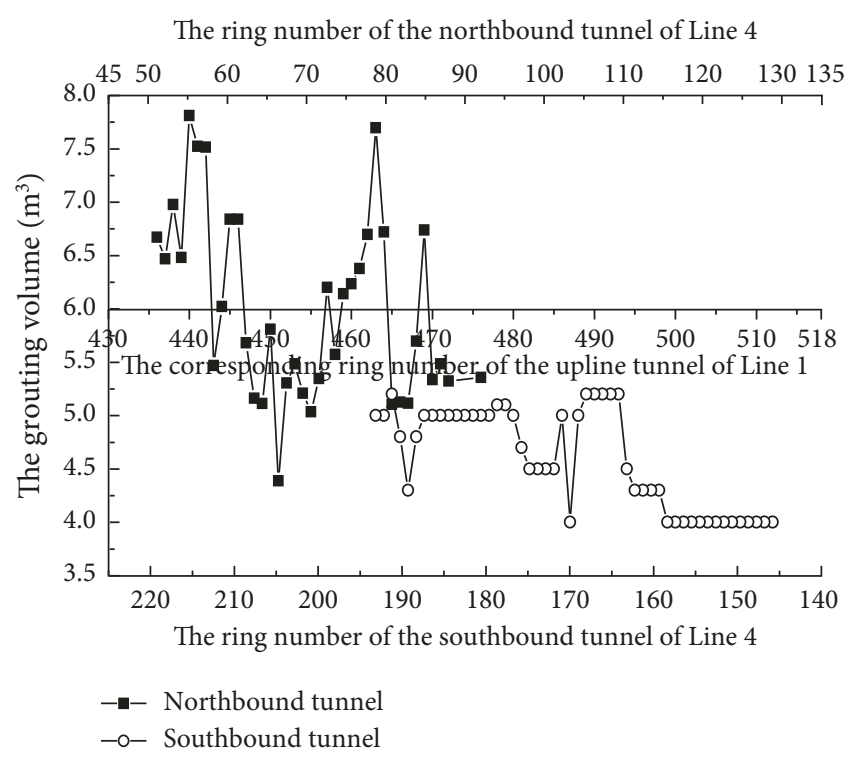

Figure 7: The grouting volume.

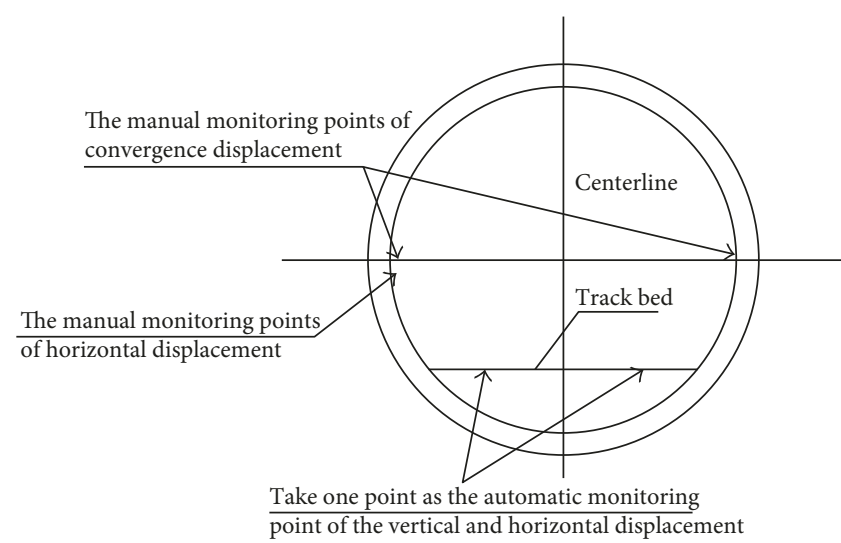

FIGURE 8: Arrangement of the monitoring points at the cross section of the existing tunnel.

leading to the reduction of the horizontal diameter of the existing tunnel. With the tunnelling of the southbound tunnel, there are a reduction negative convergence displacement on the left side of point $B$ and an addition positive convergence displacement on the right side of point B. As can be seen from Figures 10 and 11, the shapes of the convergence displacement curve and the horizontal displacement curve are similar because the causes of convergence displacement and horizontal displacement are theoretically the same.

\section{Reinforcement Scheme of the Existing Tunnel}

Figure 12 shows the reinforcement in the existing tunnel. Radial reinforcement by an arc-shaped supporting steel plate connected to the tunnel segment and longitudinal reinforcement by channel section steel to provide longitudinal tensile stress are conducted in the existing tunnel. Radial steels and longitudinal steels are connected

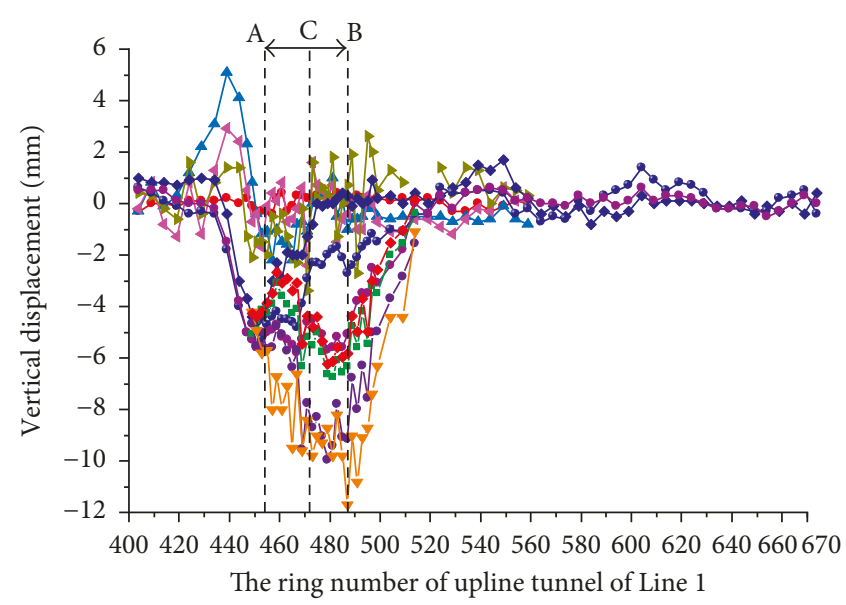

$\begin{array}{ll}\begin{array}{l}\text { The construction of } \\ \text { southbound tunnel }\end{array} & \text { The construction of } \\ \text { northbound tunnel } \\ \rightarrow \text { 2014/5/3 Ring 135 } & \rightarrow-2013 / 12 / 9 \text { Ring } 48 \\ \text { Long-term monitoring } & - \text { 2014/5/15 Ring 22013/12/27 Ring 72 } \\ \rightarrow-2014 / 6 / 5 & \rightarrow \text { 2014/1/28 Ring } 176 \\ \rightarrow-2014 / 7 / 14 & \text { The shield is shut down } \\ \rightarrow-2014 / 6 / 15 & \rightarrow-2014 / 2 / 27 \\ \rightarrow-2014 / 10 / 19 & \end{array}$

FIgURE 9: Time-varying vertical displacement of the existing tunnel.

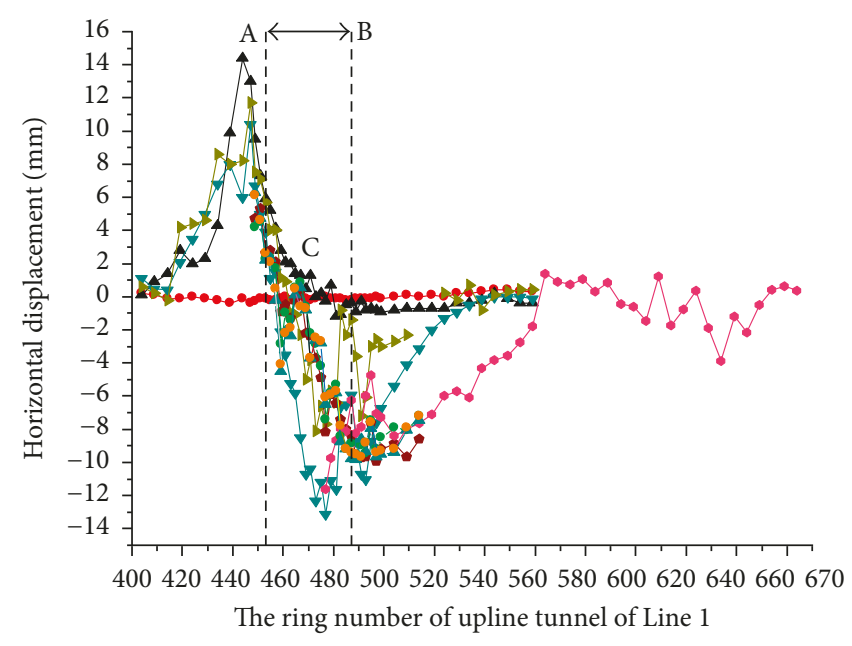

$$
\begin{array}{ll}
\text { The construction of the } & \text { The construction of the } \\
\text { southbound tunnel } & \text { northbound tunnel } \\
\rightarrow-2014 / 4 / 20 \text { Ring 36 } & \rightarrow-2013 / 12 / 9 \text { Ring } 48 \\
\rightarrow-2014 / 5 / 02 \text { Ring 124 } & \rightarrow-2013 / 12 / 27 \text { Ring } 72 \\
\rightarrow-2014 / 5 / 28 \text { Ring 270 } & \rightarrow-2014 / 1 / 5 \text { Ring } 125 \\
\text { Long-term monitoring } & \rightarrow-2014 / 1 / 28 \text { Rring } 275 \\
\rightarrow-2014 / 10 / 19 &
\end{array}
$$

FIgURE 10: Time-varying horizontal displacement of the existing tunnel.

by welding, and so, the reinforcement becomes a whole one. 25 rings are reinforced at first on either side of the intersection point $\mathrm{A}$ before the underpassing of the northbound tunnel, and the whole reinforcement is 

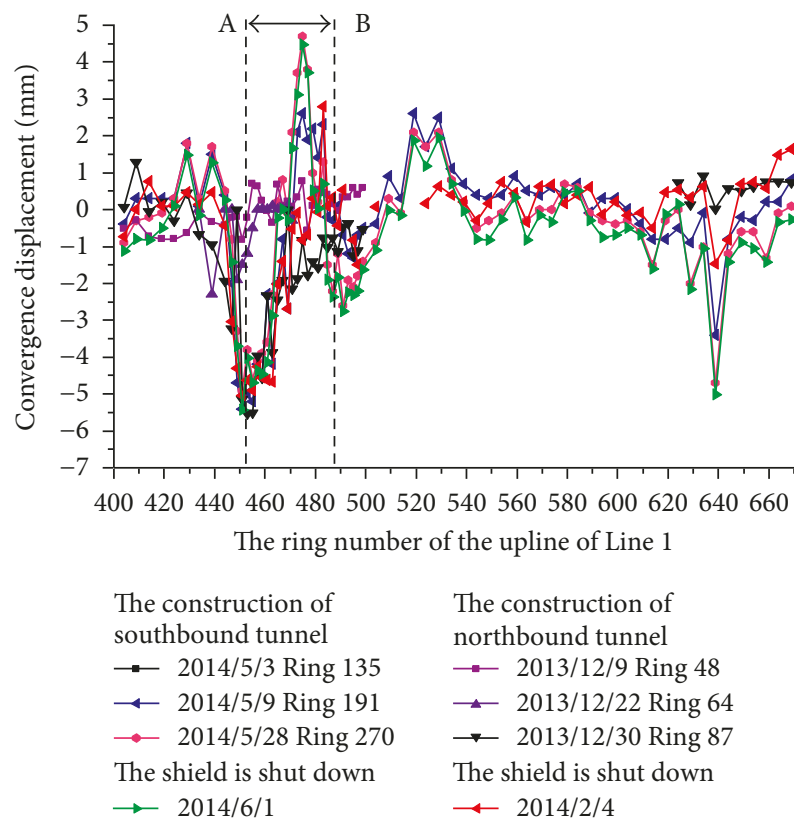

FIgURE 11: Convergence displacement of the existing tunnel.

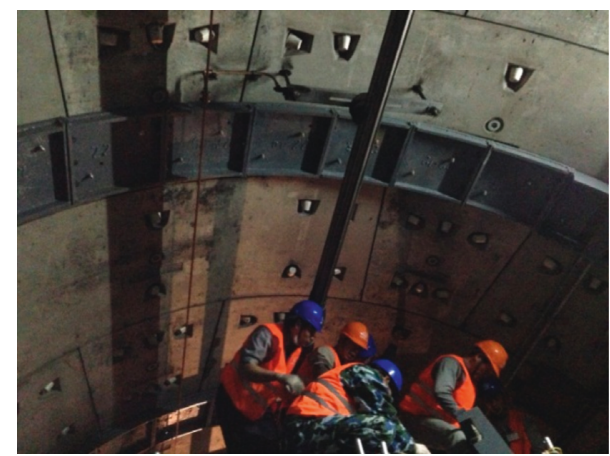

FIGURE 12: Reinforcement in the existing tunnel.

completed after the construction of the northbound tunnel. The reinforcement range is from ring 424 to ring 510 (i.e., 25 rings on either sides of the intersection points $A$ and $B)$.

\section{Theoretical Analysis of the Reinforcement Design}

The deformed tunnel lining reinforced by inner bonding steel plates has been partially or entirely used in many built tunnels or currently under construction. To better

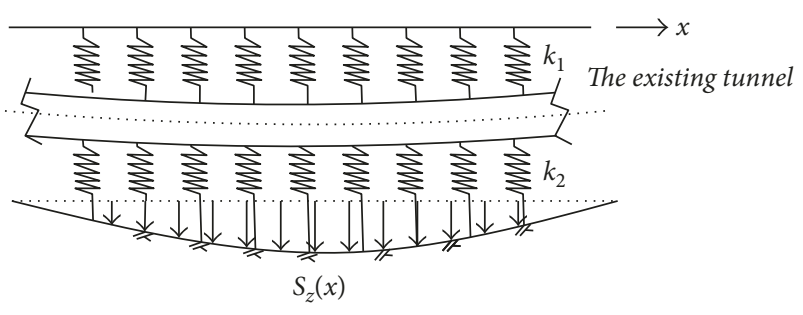

FIgUre 13: A schematic view of the existing tunnel-soil tunnelling interaction.

understand the benefits coming from the reinforcement method, the behavior of the tunnel is investigated.

Figure 13 shows a schematic view of the existing tunnel-soil tunnelling interaction. The analysis method demonstrated in this paper can be divided into two steps: firstly, estimating the greenfield displacement induced by the tunnelling. Secondly, calculating the responses of the existing tunnel subjected to the soil displacement. The method of analysis is based on three assumptions: (1) the above existing tunnel does not affect the displacement of soil due to tunnelling, (2) the soil foundation is assumed as the Winkler or the Pasternak foundation, and (3) the soil displacement is calculated by superimposing the independent settlement predicted for each individual tunnelling.

In this paper, the tunnels are considered as an infinite beam on the Winkler foundation, an infinite beam on the Pasternak foundation, and a finite beam on the Pasternak foundation (the new method). Comparing the deflection, rotation angle, normalized bending moment, and shear force of the existing tunnel with constant stiffness based on the three models, the new method is verified. Then, different stiffness of the reinforcement is taken into consideration, and the optimal reinforcement range of the existing tunnel is discussed.

6.1. The Subsurface Soil Displacement due to Tunnelling. For the theoretical analysis, the alignment of the new tunnels and the existing tunnel is assumed to be straight. Figure 14 shows a schematic diagram of the new tunnels and the existing tunnel in this case. The greenfield settlement $s(x)$ due to the tunnelling can be replaced by the equivalent distributed load $q(x)$ acting on the beam on the third assumption as follows:

$$
q(x)=k s(x) .
$$

In this study, subsurface settlement $s(x)$ at the depth of $z$ induced by tunnelling is calculated based on closed-form analytical solutions presented by Loganathan and Poulos [13] as follows:

$$
s(x)=\varepsilon_{0} R^{2}\left(\frac{z-H}{x^{2}+(z-H)^{2}}+(3-4 v) \frac{z+H}{x^{2}+(z+H)^{2}}-\frac{2 z\left(x^{2}-(z+H)^{2}\right)}{\left(x^{2}+(z+H)^{2}\right)^{2}}\right) \cdot e^{\left(-1.38 x^{2} /(H+R)^{2}-0.69 z^{2} / H^{2}\right)},
$$




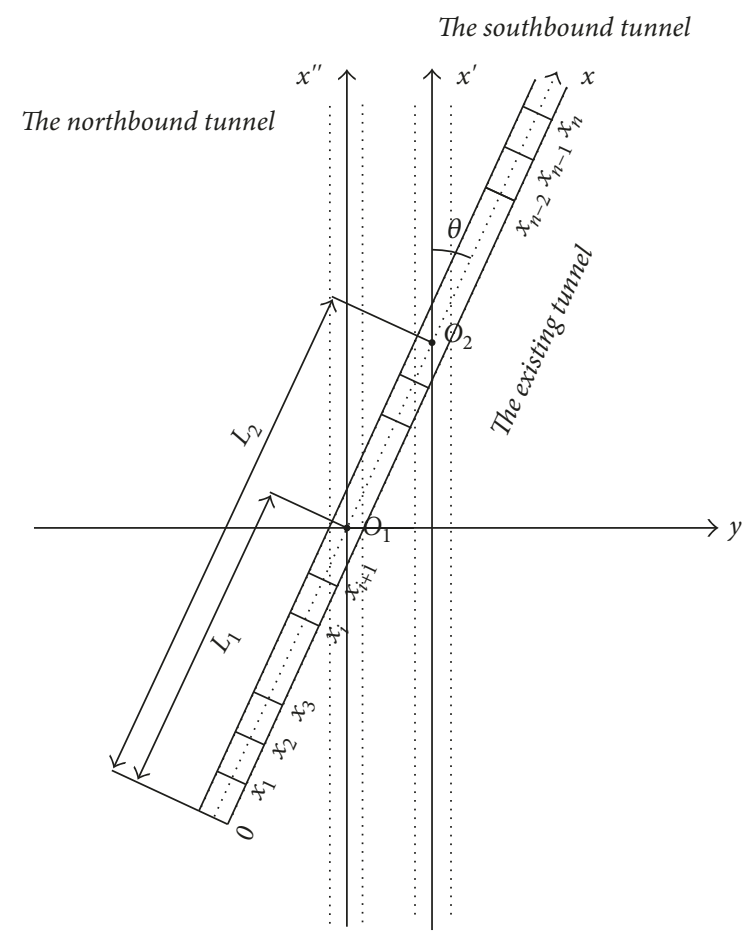

FIGURE 14: A schematic diagram of tunnels for the analytical methods.

where $s(x)=$ subsurface settlement of the soils due to tunnelling; $R$ = tunnel radius; $z=$ depth below ground surface; $H=$ depth of the axis of the new tunnel; $v=$ Poisson's ratio; $x=$ lateral distance from tunnel centerline; and $\varepsilon_{0}=$ equivalent ground loss ratio which is defined as

$$
\begin{aligned}
& \varepsilon_{0}=\frac{4 R g+g^{2}}{4 R^{2}}, \\
& g=G_{p}+u_{3 D}^{*}+w \approx G_{p},
\end{aligned}
$$

where $g$ is the gap parameter (Lee et al. [14]); $u_{3 D}^{*}$ is the three-dimensional elastoplastic deformation at the tunnel face; $w$ is the workmanship factor; and $G_{p}$ represents the physical gap between the outer skin of the shield and the lining which is given as

$$
G_{p}=2 \Delta+\delta
$$

where $\Delta$ is the thickness of the tail piece and $\delta$ is the clearance required for erection of the tail piece. The parameter $w$ can be neglected due to considerable experience with the equipment and good tunnelling technique of construction workers based on the study of Rowe and Lee [15].

6.2. Analytical Methods Derived from Prior Studies. Attewell et al. [16] proposed a tunnel-soil interaction model and solved the analytical solution of the longitudinal displacement of an infinite tunnel:

$$
\frac{\mathrm{d}^{4} w(x)}{\mathrm{d} x^{4}}+4 \lambda^{4} p(x)=4 \lambda^{4} q(x),
$$

where $q(x)$ is the concentrated load acting on the origin point of the beam; EI is the flexural stiffness of a tunnel, which is recommended by Ye et al. [17]; and $k$ is the subgrade modulus that represents the pipe-soil interaction.

If the soil foundation is assumed as the Winkler foundation, the foundation counterforce $p(x)$ can be expressed as

$$
p(x)=k w(x)
$$

The two-parameter model of foundation can capture the shear resistance of soil. Based on the assumption of the plane strain condition, the displacement of ground in the $y$-direction is neglected. If the soil foundation is assumed as the Pasternak foundation, the foundation counterforce $p(x)$ can be expressed as

$$
p(x)=-G \nabla^{2} w(x)+k w(x),
$$

where $G$ is the coefficient of the shear element in the Pasternak's model with the dimension of force per unit length.

Attewell et al. [16] presented a solution for the concentrated load $q$ on an infinite beam resting on the Winkler foundation and computed the deflection as

$$
w(x)=\frac{1}{8 E I \lambda^{3}} q e^{-\lambda x}(\cos \lambda x+\sin \lambda x) .
$$

It can be concluded that each of the concentrated load $k s(\tau)$ at point $\tau$ contributes the following amount to the deflection of the existing tunnel on the Winkler foundation:

$$
\begin{aligned}
w(x)= & \frac{1}{8 E I \lambda^{3}} \int_{-\infty}^{+\infty} 2 \operatorname{Rks}\left(\left(t-L_{1}\right) \sin \alpha\right) e^{-\lambda|x-\tau|} \\
& (\cos \lambda|x-\tau|+\sin \lambda|x-\tau|) \mathrm{d} \tau,
\end{aligned}
$$

where $L_{1}$ is the distance between the coordinate origin of the existing tunnel and the intersection point between the new tunnel and the existing tunnel and $\alpha$ is the intersection angle between the new tunnel and existing tunnel. The deflection, rotational angle, bending moment, and shear force of the existing tunnel which is assumed as an infinite beam on the Winkler foundation and the Pasternak foundation are illustrated in Appendix A.

6.3. A BriefDescription of the New Method. In this study, we want to figure out the effects of the reinforcement on the existing tunnel, the stiffness varies in this case and the existing tunnel assumed as an infinite beam is not suitable. Assuming the existing tunnel with finite length and introducing (7) to (9), the basic differential equation governing the flexure of the beam resting on the Pasternak foundation can be written in the form with an assumption of $G \lambda^{2} / k<1$ :

$$
E_{i} I_{i} \frac{\mathrm{d}^{4} w_{i}(x)}{\mathrm{d} x^{4}}-G_{i} b_{i} \frac{\mathrm{d}^{2} w_{i}(x)}{\mathrm{d} x^{4}}+k_{i} b_{i} w_{i}(x)=b_{i} q_{i}(x),
$$

where $b_{1 i}=b_{i}\left(1+\left(\sqrt{G_{i} / k_{i}} / b_{i}\right)\right)$, subscript $i$ represents the $i$ th element of the beam, $b_{i}$ is the width of the beam, and $b_{1 i}$ is the modified width of the beam. Assuming a solution of (12) in the form of $w(x)=e^{\lambda x}$, the general solution of vertical displacement of the beam is as follows: 


$$
w(x)=\sum_{i=1}^{4} C_{i} F_{i}(x)
$$

where $C_{i}(i=1,2,3,4)$ are undetermined parameters, which are dependent on the boundary conditions, and $F_{i}(x)$ $(i=1,2,3,4)$ are the basic functions of the general solution, which are given as follows:

$$
\begin{aligned}
& F_{1 i}(x)=\cos \left(a_{1 i} c_{i} x\right) \sinh \left(a_{2 i} c_{i} x\right), \\
& F_{2 i}(x)=\cos \left(a_{1 i} c_{i} x\right) \cosh \left(a_{2 i} c_{i} x\right), \\
& F_{3 i}(x)=\sin \left(a_{1 i} c_{i} x\right) \cosh \left(a_{2 i} c_{i} x\right), \\
& F_{4 i}(x)=\sin \left(a_{1 i} c_{i} x\right) \sinh \left(a_{2 i} c_{i} x\right),
\end{aligned}
$$

where $c_{i}=\sqrt[4]{k_{i} b_{1} / 4 E_{i} I_{i}}, a_{1 i}=\sqrt{1-G_{i} c_{i}^{2} / k_{i}}, a_{2 i}=\sqrt{1+G_{i} c_{i}^{2} / k_{i}}$.

The relationship of the deflection, rotational angle, bending moment, and shear force of the beam proposed by Lancaster and Mitchell [18] is as follows:

$$
\begin{aligned}
\theta_{i}(x) & =w_{i}^{\prime}(x), \\
M_{i}(x) & =-E_{i} I_{i} w^{\prime \prime}(x), \\
Q_{i}(x) & =-E_{i} I_{i} w^{\prime \prime \prime}(x)+G_{p i} b_{1 i} w_{i}^{\prime}(x),
\end{aligned}
$$

where $\theta_{i}(x), M_{i}(x)$, and $Q_{i}(x)$ are the amplitudes of rotational angle, bending moment, and shear force of the section area, respectively.

Figure 15 shows that different stiffness is replaced by equivalent stepped stiffness. According to different stiffness and distributed load, the local coordinate system is established as illustrated in Figure 16. Selvadurai [12] suggests an initial parameter method to solve the parameters of the beam. The four parameters at the origin of the coordinates are $w_{i}\left(0_{i}\right), \theta_{i}\left(0_{i}\right), M_{i}\left(0_{i}\right)$, and $Q_{i}\left(0_{i}\right)$, and four parameters at the end of the element are $w_{i}\left(x_{i}\right), \theta_{i}\left(x_{i}\right), M_{i}\left(x_{i}\right)$, and $Q_{i}\left(x_{i}\right)$. $C_{1}, C_{2}, C_{3}$, and $C_{4}$ can be expressed by $w_{i}\left(0_{i}\right), \theta_{i}\left(0_{i}\right)$, $M_{i}\left(0_{i}\right)$, and $Q_{i}\left(0_{i}\right)$ by introducing $x_{i}=0$ to (13) and (18).

$w_{i}\left(x_{i}\right), \theta_{i}\left(x_{i}\right), M_{i}\left(x_{i}\right)$, and $Q_{i}\left(x_{i}\right)$ can be rewritten in the matrix-array form as

$$
\left[\begin{array}{l}
w_{i}\left(x_{i}\right) \\
\theta_{i}\left(x_{i}\right) \\
M_{i}\left(x_{i}\right) \\
V_{i}\left(x_{i}\right) \\
1
\end{array}\right]=\left[\begin{array}{lllll}
k_{11} & k_{12} & k_{13} & k_{14} & k_{15} \\
k_{21} & k_{22} & k_{23} & k_{24} & k_{25} \\
k_{31} & k_{32} & k_{33} & k_{34} & k_{35} \\
k_{41} & k_{42} & k_{43} & k_{44} & k_{45} \\
0 & 0 & 0 & 0 & 1
\end{array}\right] \cdot\left[\begin{array}{l}
w_{i}\left(0_{i}\right) \\
\theta_{i}\left(0_{i}\right) \\
M_{i}\left(0_{i}\right) \\
V_{i}\left(0_{i}\right) \\
1
\end{array}\right],
$$

where $\left[k_{i j}\right]$ is a stiffness submatrix with $5 \times 5$ order; $i$, $j=1,2, \ldots, 5 . M$ and $V$ are, respectively, the bending moment and the generalized shear force. Formula (19) can be simplified as

$$
N_{i}\left(x_{i}\right)=K_{i j} N_{i}\left(0_{i}\right) \text {, }
$$

where $N_{i}\left(x_{i}\right)=\left[W_{i}\left(x_{i}\right), \theta_{i}\left(x_{i}\right), M_{i}\left(x_{i}\right), Q_{i}\left(x_{i}\right), 1\right]^{T}$ and $N_{i}\left(0_{i}\right)=\left[W_{i}\left(0_{i}\right), \theta_{i}\left(0_{i}\right), M_{i}\left(0_{i}\right), Q_{i}\left(0_{i}\right), 1\right]^{T}$.

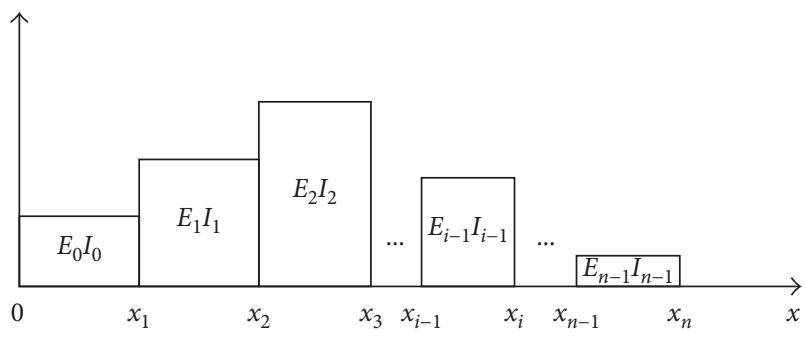

Figure 15: Sketch of equivalent stepped stiffness.

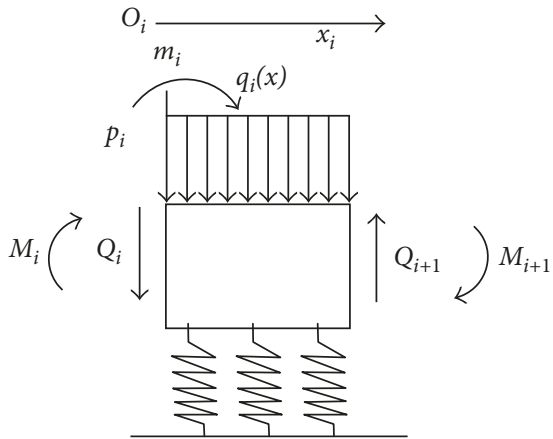

FIgURE 16: Forces and local coordinate system.

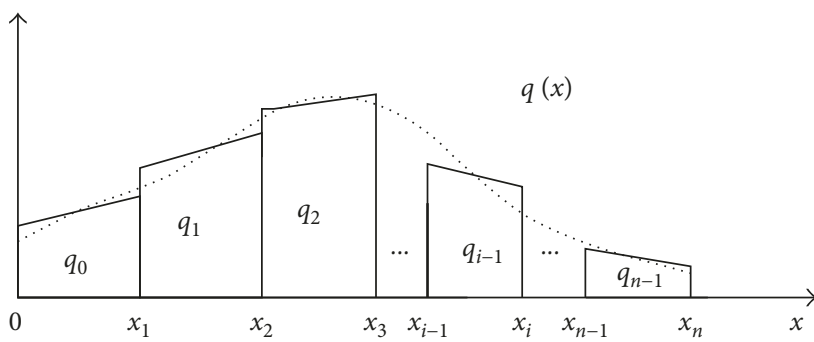

FIgURE 17: Replacement of variable load with trapezoid load.

Figure 17 shows that curved distributed load is replaced by equivalent triangular and square distributed load which can be expressed as

$$
q_{i-1}+\triangle q_{i}=q_{i-1}+\xi\left(\frac{q_{i}-q_{i-1}}{L_{i}}\right),
$$

where $q_{i-1}$ and $q_{i}$ are, respectively, the load of the starting point and the ending point of the $i$ th element and $\xi$ is the position of arbitrary load. From (19), we can obtain

$k_{15}=-\frac{b \int_{0}^{x}\left(q_{i-1}+\triangle q_{i}\right)\left(a_{2 i}^{-1} F_{1 i}[x-\xi]-a_{1 i}^{-1} F_{3 i}[x-\xi]\right) d \xi}{4 c_{i}^{3} E_{i} I_{i}}$.

In order to avoid numerical errors in the calculation process, the integration of $k_{i 5}$ is shown in Appendix B. The rest of $k_{i j}$ can be referred in the work by Selvadurai [12].

Figure 18 shows the tunnel matrix transfer diagram. Assuming that the tunnel is composed of $N$ elements, the $x$-coordinate of beginning points of the $i$ th element is $x_{i}(i=0,1,2, \ldots n)$ and the length of each element is $L_{i}$, where $L_{i}=x_{i}-x_{i-1}$. 


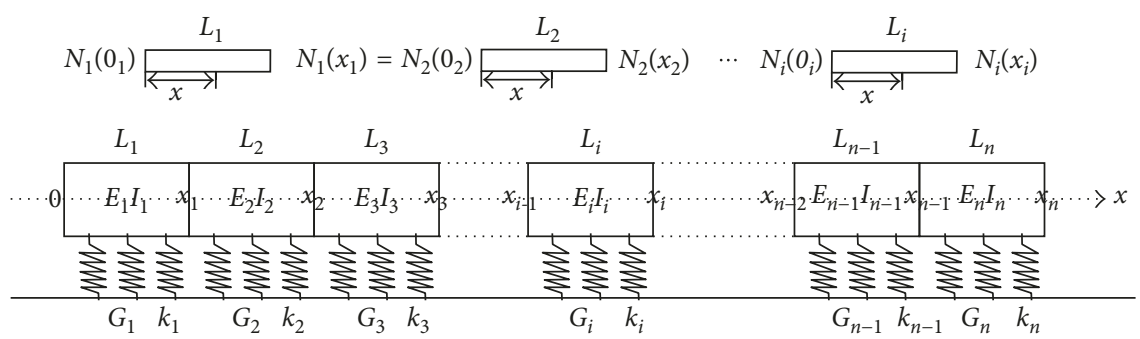

Figure 18: The matrix transfer diagram.

For the first element,

$$
N_{1}(x)=K_{1}(x) \cdot N_{1}\left(0_{1}\right) \quad x \in\left(0, L_{1}\right) .
$$

For the end point of the first element,

$$
N_{1}\left(x_{1}\right)=K_{1}\left(x_{1}-0\right) \cdot N_{1}\left(0_{1}\right) .
$$

For the end point of the $i$ th element,

$N_{i}\left(x_{i}\right)=K_{i}\left(x_{i}\right) \cdot K_{i-1}\left(L_{i-1}\right) \cdot K_{i-2}\left(L_{i-2}\right) \cdots K_{1}\left(L_{1}\right) \cdot N_{1}\left(0_{1}\right)$.

For $x$ at the ith element section, where $x$ is a global coordinate,

$N_{\mathrm{i}}(x)=K_{i}\left(x-x_{i-1}\right) \cdot K_{i-1}\left(L_{i-1}\right) \cdot K_{i-2}\left(L_{i-2}\right) \cdots K_{1}\left(L_{1}\right) \cdot N_{1}\left(0_{1}\right)$.

\section{Suppose}

$$
A_{\mathrm{i}}(x)=K_{i}\left(x-x_{i-1}\right) \cdot K_{i-1}\left(L_{i-1}\right) \cdot K_{i-2}\left(L_{i-2}\right) \cdots K_{1}\left(L_{1}\right) .
$$

Then, (20) can be expressed as

$$
N_{i}(x)=A_{i}(x) \cdot N_{1}\left(0_{1}\right) .
$$

Thus, the relation between the vector $N_{n}\left(x_{n}\right)$ at the point $x_{n}$ and the vector $N_{1}\left(0_{1}\right)$ at the start point $x_{0}$ is

$$
N_{n}\left(x_{n}\right)=A_{n}\left(x_{n}\right) \cdot N_{1}\left(0_{1}\right) \text {, }
$$

where

$$
A_{\mathrm{n}}\left(x_{n}\right)=\prod_{i=n}^{1} K_{i}\left(L_{i}\right) .
$$

The boundary condition of the existing tunnel assumed as an infinite long tunnel considering the shear stress of soil can be written as

$$
\begin{aligned}
& M(0)=0, \\
& V(0)=2 \sqrt{\frac{k}{G} \cdot G \cdot R \cdot w(0),} \\
& V(L)=0, \\
& V(L)=-2 \sqrt{\frac{k}{G}} \cdot G \cdot R \cdot w(L) .
\end{aligned}
$$

By applying the boundary conditions to (19), the deflection, rotational angle, bending moment, and shear force of the overall beam can be obtained.

\subsection{Case Study}

6.4.1. Parameter Selection. To enable a direct comparison, assumed parameters of the soil and existing tunnel are selected in this study. Poisson's ratio of the soil is 0.388 . The grouting process is regarded as the inverse process of soil loss due to tunnelling, and $g$ can be expressed as $g=(2 \Delta+\delta)(1-\eta)$, where $\eta$ is the injection ratio.

For the Pasternak foundation, as the thickness of the elastic layer is assumed to be $2.5 \mathrm{~B}$, the subgrade elastic modulus $k$ and shear stiffness $G$ are suggested by Xu [19] as follows:

$$
\begin{aligned}
k & =\frac{5 E_{0} \beta}{16\left(1-v_{0} .5 p t^{2}\right)} \times 1.22, \\
G & =\frac{13 E_{0} B^{2}}{32\left(1+v_{0}\right) \beta} \times 0.85,
\end{aligned}
$$

where $\beta$ is a modified parameter $(\beta=1.29)$ and $E_{0}$ and $v_{0}$ are, respectively, the elastic modulus and Poisson's ratio for elastic foundation, which are given as follows:

$$
\begin{gathered}
E_{0}=\frac{E_{s}}{1-v_{s}^{2}}, \\
v_{0}=\frac{v_{s}}{1-v_{s}},
\end{gathered}
$$

where the empirical relation between the Young's modulus $E_{s}$ and the compression modulus $E_{s 0.1-0.2}$ of soft soils is built up by Yang and Zhao [20].

$$
E_{0}=(2.5 \sim 3.5) E_{s 0.1-0.2} .
$$

As illustrated in Figure 14, points $O_{1}$ and $O_{2}$ are, respectively, the intersection points $\mathrm{A}$ and $\mathrm{B}$; in practical, coordinate transformation expressions of the axis $x^{\prime}$ and $x^{\prime \prime}$ are, respectively,

$$
\begin{aligned}
& x^{\prime}=\left(x-L_{1}\right) \sin \alpha, \\
& x^{\prime \prime}=\left(x-L_{2}\right) \sin \alpha,
\end{aligned}
$$

where $L_{1}$ and $L_{2}$ are the distance from the beginning point of the existing tunnel to points $\mathrm{O}_{1}$ and $\mathrm{O}_{2}$, respectively. The length of the existing tunnel is assumed as $250 \mathrm{~m}$, and the ring spacing is $1.2 \mathrm{~m}$. So, the tunnel is divided into 209 sections, and each section is $1.2 \mathrm{~m}$ in length. 
The ring number of the existing tunnel

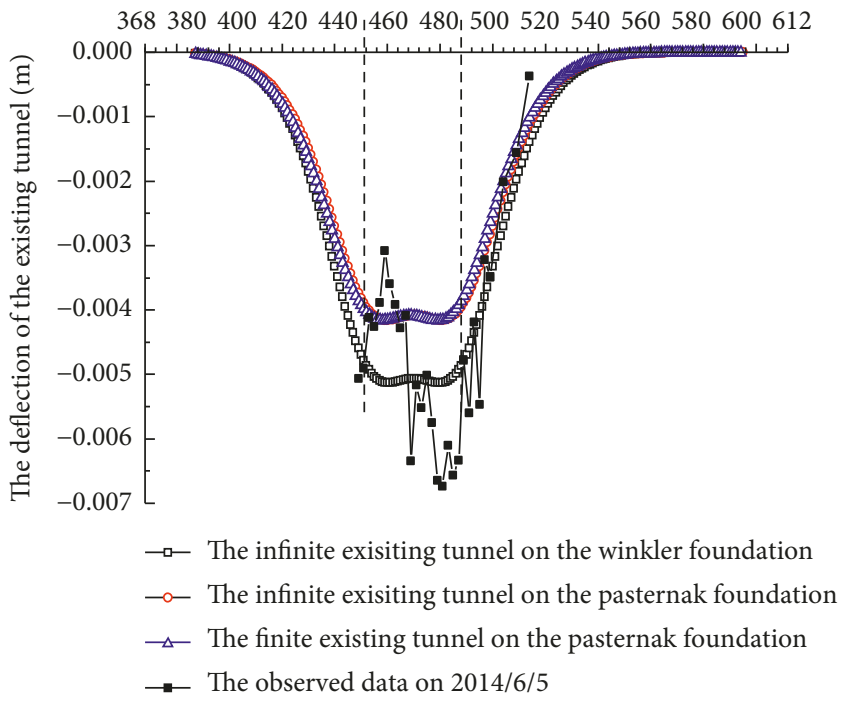

(a)

The ring number of the existing tunnel

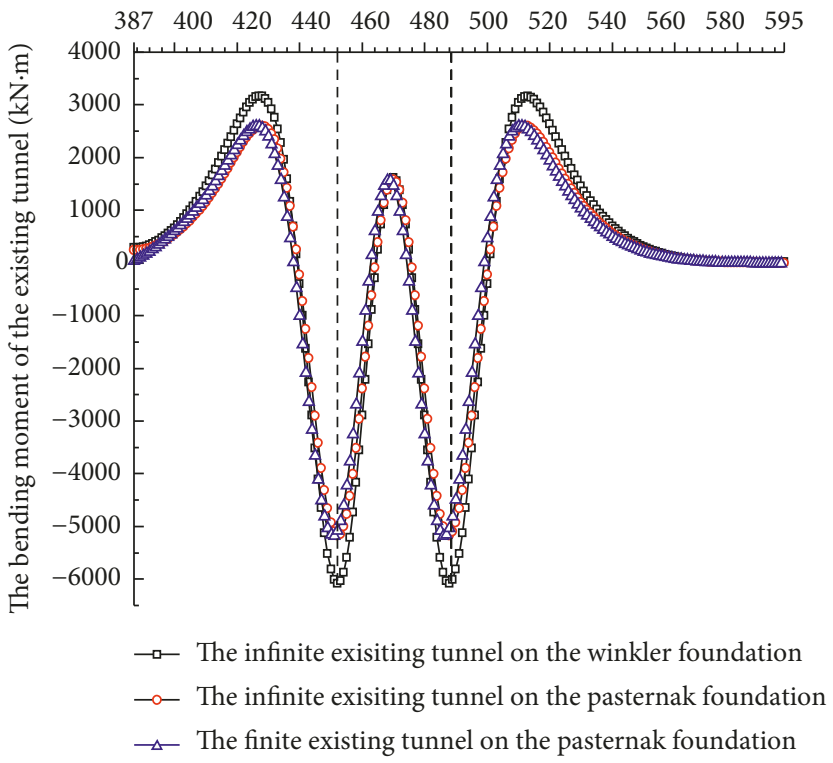

(c)

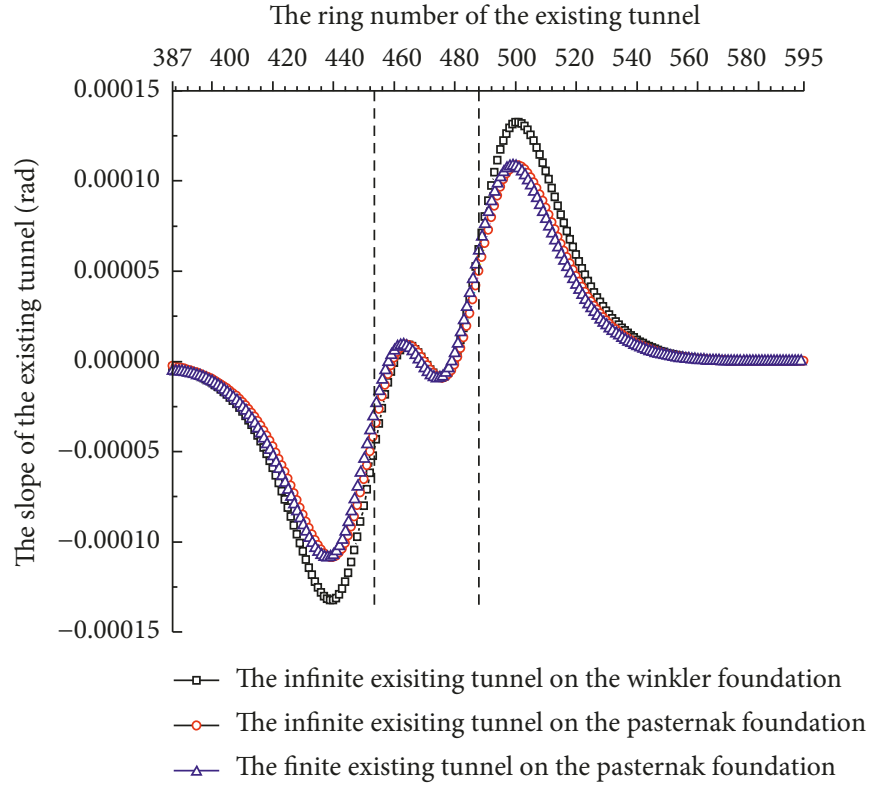

(b)

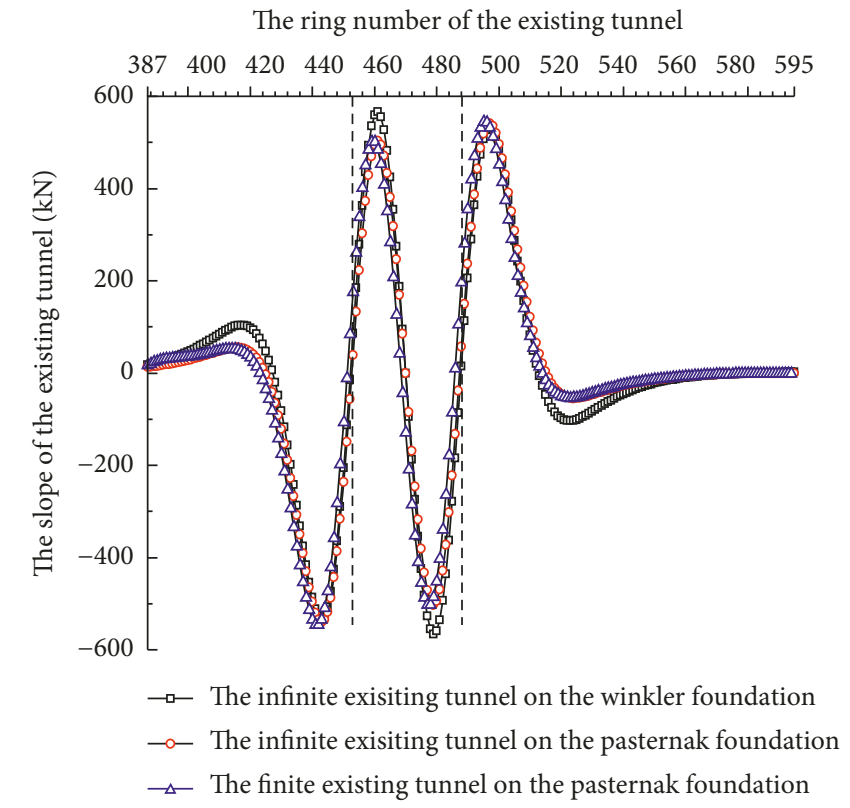

(d)

Figure 19: (a) Comparison of the deflection of the existing tunnel using different models. (b) Comparison of the rotational angle of the existing tunnel using different models. (c) Comparison of the normalized bending moment of the existing tunnel using different models. (d) Comparison of the normalized shear force of the existing tunnel using different models.

\section{Discussions}

The normalized bending moment and shear force are defined as

$$
\begin{array}{r}
\tilde{M}_{i}=\frac{M_{i} L_{0}}{E_{i} I_{i}}, \\
Q_{i}=\frac{Q_{i} L_{0}^{2}}{E_{i} I_{i}},
\end{array}
$$

where $\tilde{M}_{i}$ and $Q_{i}$ are, respectively, the normalized bending moment and shear force; $M_{i}$ and $Q_{i}$ are, respectively, the calculated bending moment and shear force; and $L_{0}$ is the length of the existing tunnel.

Figure 19 shows the comparison of the deflection, rotational angle, bending moment, and shear force of the existing tunnel with a constant stiffness which is based on three kinds of models: an infinite tunnel on the Winkler foundation, an infinite tunnel on the Pasternak foundation, and a finite tunnel on the Winkler foundation. Note that the 


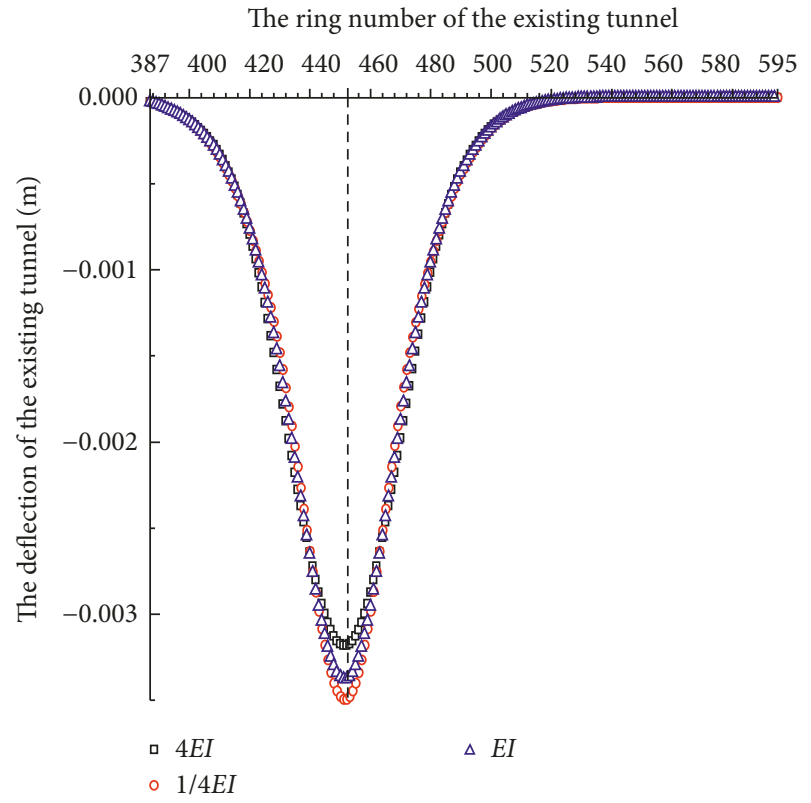

(a)

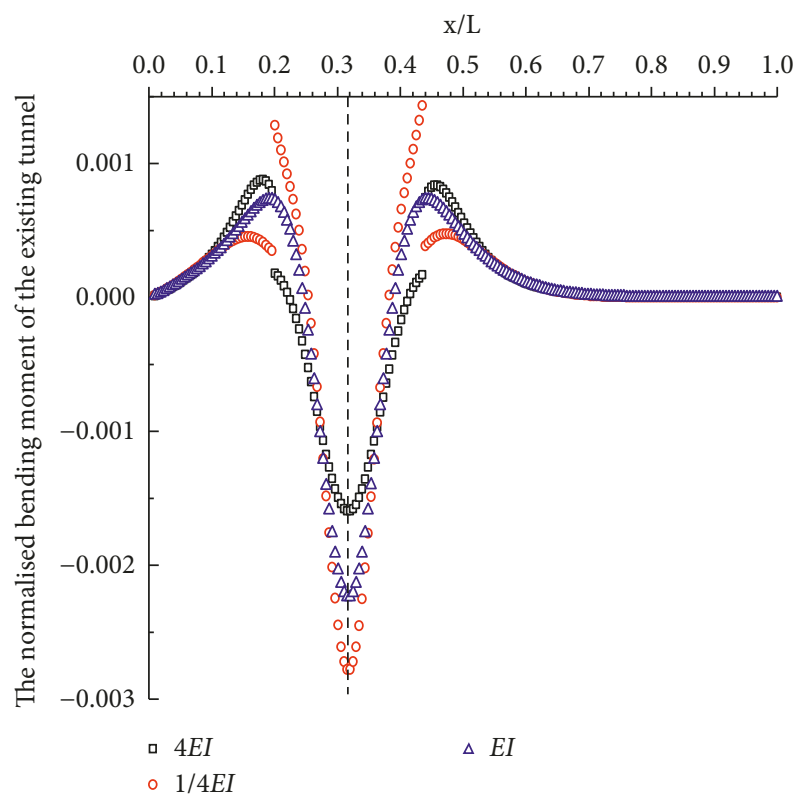

(c)

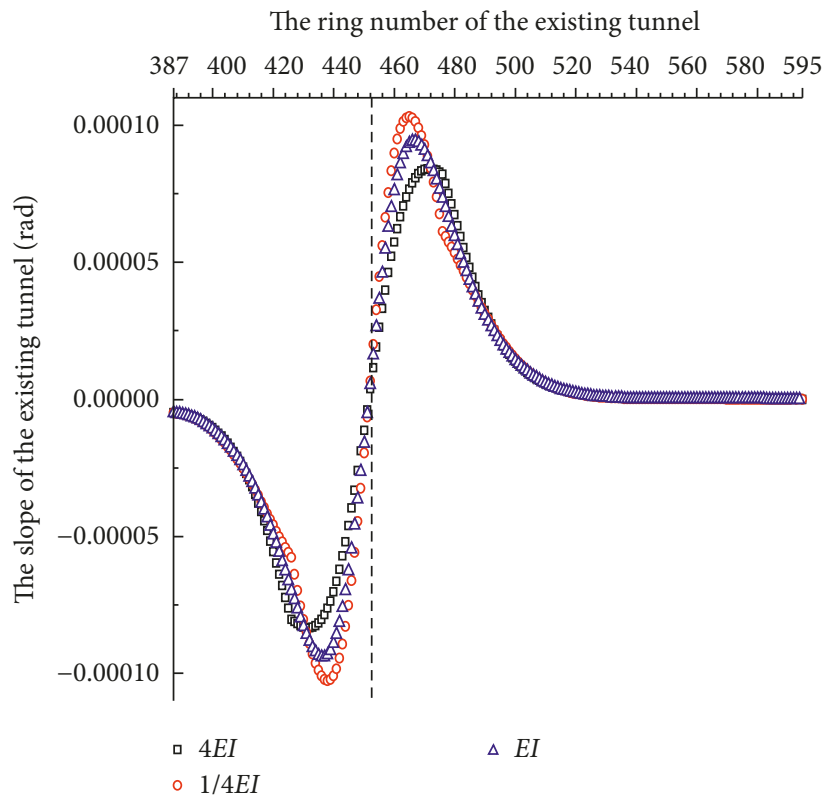

(b)

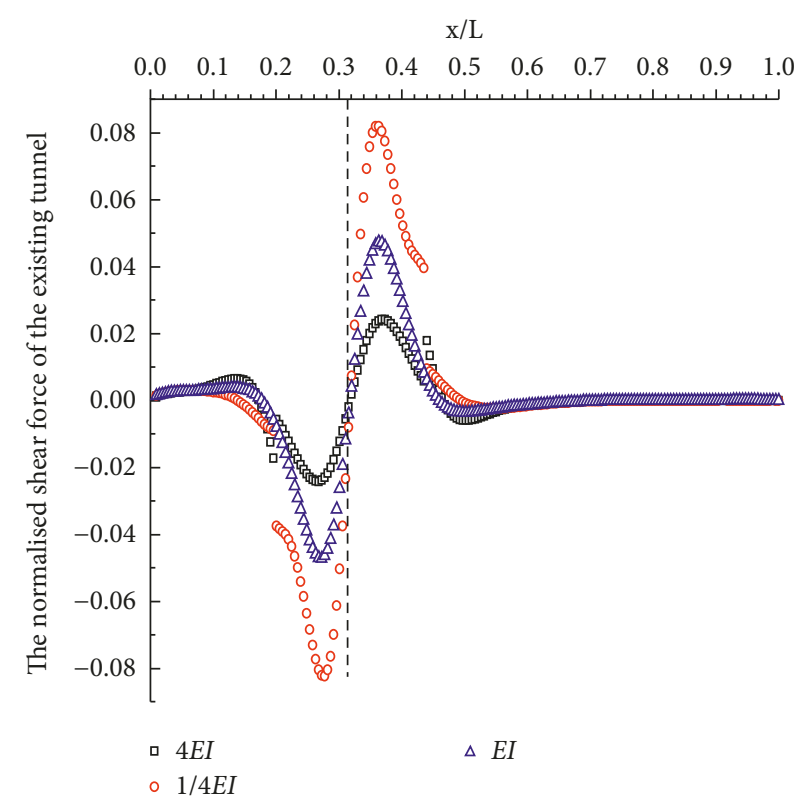

(d)

Figure 20: (a) The effects of different reinforcement stiffness on the deflection of the existing tunnel. (b) The effects of different reinforcement stiffness on the slope of the existing tunnel. (c) The effects of different reinforcement stiffness on the normalized moment of the existing tunnel. (d) The effects of different reinforcement stiffness on the normalized shear force of the existing tunnel.

existing tunnel is only subject to soil deformation force in this case. The displacement and the deflection of beam are particular similar concepts owing to the fact that the existing tunnel is securely attached to the foundation, generally without rigid body motion. Fairly good agreement can be observed between the infinite tunnel on the Pasternak foundation and the finite tunnel on the Pasternak foundation, which shows that the method proposed in this paper is correct and can be used to analyze similar problems. Because of considering soil shear stress, vertical stress and deformation are affected and weakened; the displacement of the existing tunnel on the Pasternak foundation is smaller than that on the Winkler foundation without considering the shear stress of soil. Using the Winkler foundation model is in good agreement with the observed data. It can be seen from (3) that the displacement of the existing tunnel is proportional to the grouting efficiency (i.e., $\eta$ ). Due to the uncertainty of $\eta$, it cannot be decided which one is the best analytical method. It is clear that the maximum normalized bending moment occurs at the points $O_{1}$ and $O_{2}$, which are the nearest points between the existing tunnel and the new tunnels. 


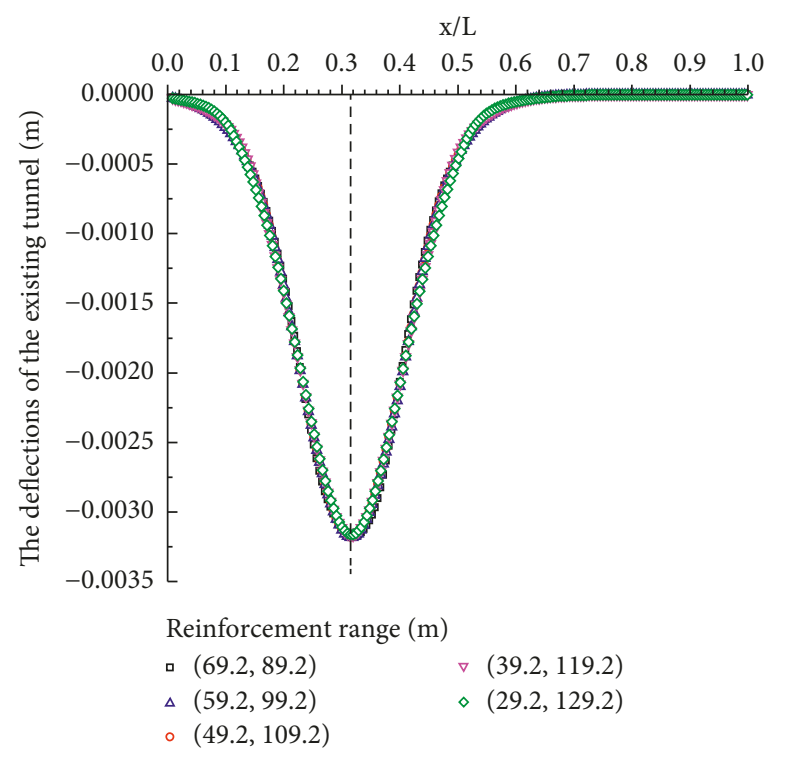

(a)

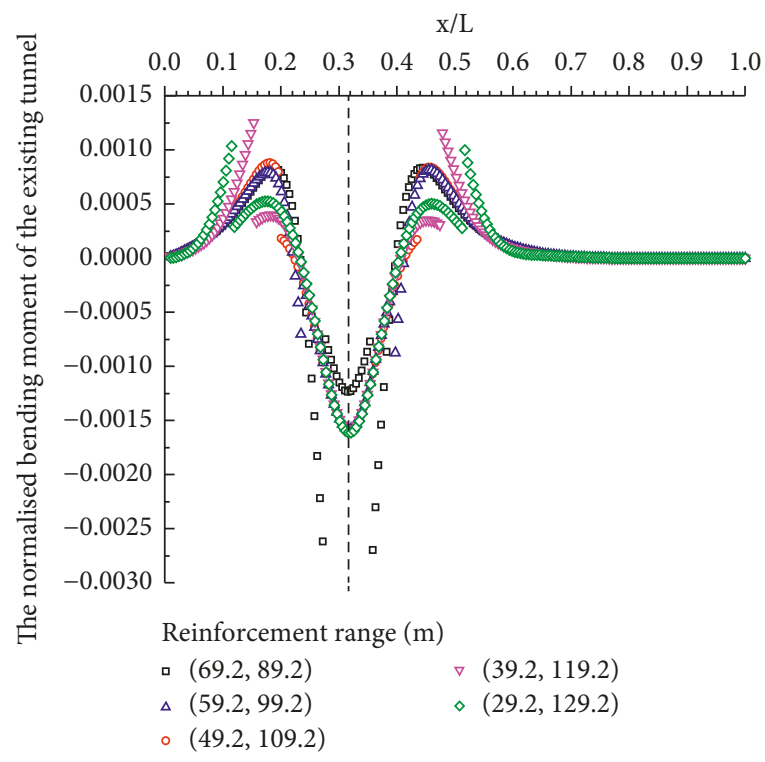

(c)

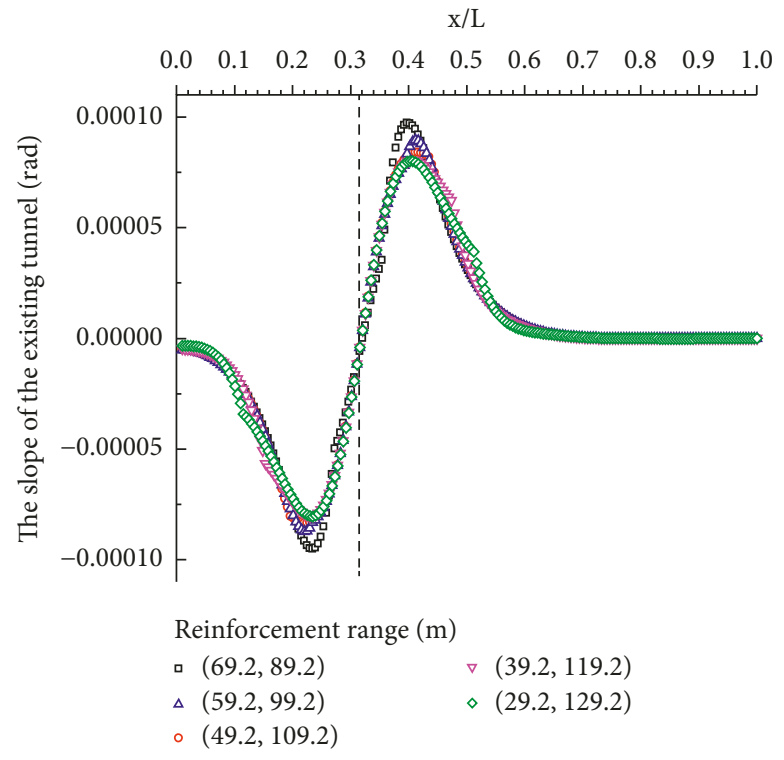

(b)

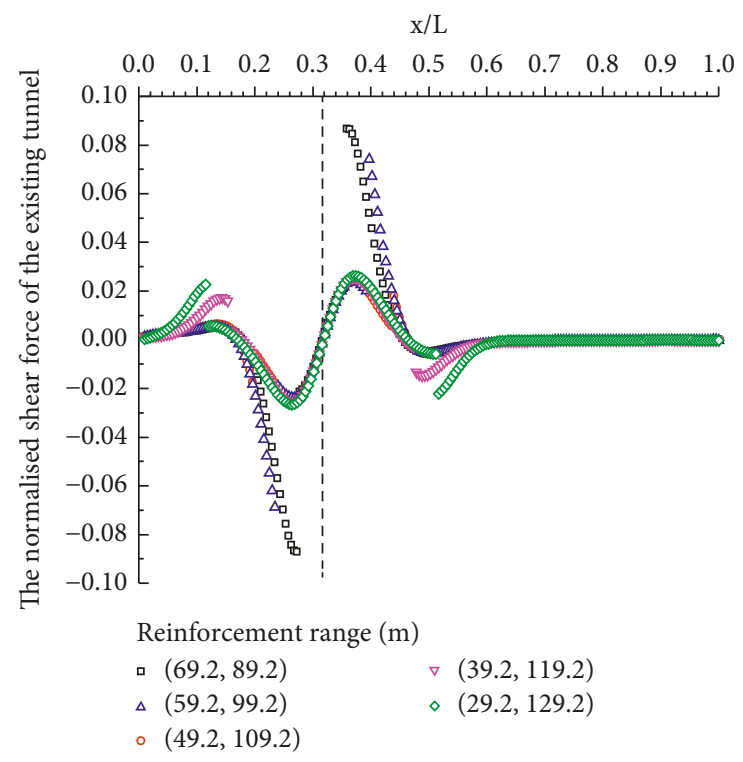

(d)

Figure 21: (a) The effects of different reinforcement ranges on the deflection of the existing tunnel. (b) The effects of different reinforcement ranges on the slope of the existing tunnel. (c) The effects of different reinforcement ranges on the normalized moment of the existing tunnel. (d) The effects of different reinforcement ranges on the normalized shear force of the existing tunnel.

The reinforce range of the existing tunnel is assumed as 25 rings on either side of the intersection point $\mathrm{A}$ and the various stiffness is taken into consideration using the method proposed in this paper. Figure 20 shows the influence of different stiffness of the reinforcement on the existing tunnel (i.e., $4 E I, E I$, and $1 / 4 E I$ ). It is evident that the reinforcement can reduce the displacement, rotational angle, normalized bending moment, and shear force of the existing tunnel, while tunnel damage (reduce the stiffness of reinforcement) has the opposite effect. It is evident that the change of reinforcement stiffness has greater effect on the normalized bending moment and the normalized shear force of the existing tunnel, particularly at the inflection points of the normalized bending moment and normalized shear force curve.

The reinforce stiffness of the reinforcement range is assumed as $4 E I$ and the various reinforcement ranges is taken into consideration using the method proposed in this paper. Figure 21 shows the influence of different reinforcement ranges on the existing tunnel when the northbound tunnel of Line 4 underpasses. The normalized bending moment on either side of the intersection point is too large when the reinforcement range is $69-89.2 \mathrm{~m}$, and the normalized shear force on either side of the intersection point is relatively too large when the reinforcement range is less than $59.2-99.2 \mathrm{~m}$. So, it is necessary to reinforce larger 
than the range of $49.2-109.2 \mathrm{~m}$ in the existing tunnel in this case, that is, larger than $30 \mathrm{~m}$ ( 25 rings) on either side of the intersection point. There is no big difference in the bending moment and shear force of the existing tunnel when the reinforcement ranges are 49.2-109.2 $\mathrm{m}, 39.2-119.2 \mathrm{~m}$, and 29.2-129.2 m. In order to reduce the costs of reinforcement, reinforcement in the $30 \mathrm{~m}$ range (i.e., 25 rings) on either side of the intersection point is the best choice which verifies the actual design.

\section{Conclusions}

Based on the abovementioned statements, the response of the existing tunnel is analyzed, and analytical methods are proposed for verification and the reinforcement design. Main conclusions derived from the analysis are as follows:

(1) The displacement of the existing tunnel changes with the relative position of the shield and the existing tunnel. Shield parameters have a major impact on the existing tunnel. The heaves of the existing tunnel might be caused by the large applied face pressure and bulkhead addictive thrust. When the shield tail is driving beyond the selected monitoring rings, the selected monitoring rings settle rapidly due to the closure of the shield tail void.

(2) The southbound tunnel of Line 4 has less effect on the left side of the intersection point $A$ on the existing tunnel because of the northbound tunnel's barrier effect. A variety of measures of displacement prevention of Line 1 such as the control of shield parameters, reinforcement of the existing tunnel can ensure the normal operation of metro Line 1.

(3) The analytical method proposed in the paper is verified by the methods derived from prior studies. It is possible to take the different stiffness and curved loads into account by applying the stepped stiffness and trapezoidal load while using a local coordinate system in the derivation of the new method. The change of reinforcement stiffness has greater effect on the normalized bending moment and the normalized shear force of the existing tunnel, particularly at the inflection points of the normalized bending moment and normalized shear force curve. The analytical method can be applied for the reinforcement design and safety check of the built tunnel.

\section{Appendices}

\section{A.1. An Infinite Beam on the Winkler Foundation}

$\theta(x)=\int_{-\infty}^{+\infty}\left\{\begin{array}{c}-\lambda^{2} \frac{s((t-L) \sin \alpha) e^{-\lambda(x-t)} \sin (\lambda(x-t))}{b} \\ \lambda^{2} \frac{s((t-L) \sin \alpha) e^{\lambda(x-t)} \sin (\lambda(t-x))}{b}\end{array}\right\} d t$

$$
\begin{aligned}
& M(x)=\frac{1}{4 \lambda} \int_{-\infty}^{+\infty} k s((t-L) \sin \alpha) e^{-\lambda|x-t|}(\cos (\lambda|x-t|)-\sin (\lambda|x-t|)) d t, \\
& Q(x)=\int_{-\infty}^{+\infty}\left\{\begin{array}{cc}
-\frac{1}{2} k s((t-L) \sin \alpha) e^{-\lambda(x-t)} \cos (\lambda(x-t)) d t & x-t>0 \\
\frac{1}{2} k s((t-L) \sin \alpha) e^{-\lambda(t-x)} \cos (\lambda(t-x)) d t & x-t \leq 0
\end{array}\right\} d t .
\end{aligned}
$$

\section{A.2. An Infinite Beam on the Pasternak Foundation}

$$
\begin{aligned}
& w(x)=\frac{\lambda}{2 b k} \int_{-\infty}^{+\infty} k s((t-L) \sin \alpha) D e^{-a_{1} \lambda|x-\tau|}\left(\frac{1}{a_{1}} \cos \left(a_{2} \lambda|x-\tau|\right)+\frac{1}{a_{2}} \sin \left(a_{2} \lambda|x-\tau|\right)\right) d \tau \\
& \theta(x)=\int_{-\infty}^{+\infty}\left\{\begin{array}{c}
-\lambda^{2} \frac{s((t-L)) e^{-a 1 \lambda(x-t)} \sin \left(a_{2}(x-t)\right)}{a_{1} a_{2} b} \\
\lambda^{2} \frac{s((t-L)) e^{a 1 \lambda(x-t)} \sin \left(a_{2}(t-x)\right)}{a_{1} a_{2} b}
\end{array}\right\} d t,
\end{aligned}
$$




$$
\begin{aligned}
& M(x)=\frac{1}{4 \lambda} \int_{-\infty}^{+\infty} k s((t-L) \sin \alpha) e^{-a_{1} \lambda|x-t|}\left(\frac{1}{a_{1}} \cos \left(a_{2} \lambda|x-t|\right)-\frac{1}{a_{2}} \sin \left(a_{2} \lambda|x-t|\right)\right) d t \\
& Q(x)=\int_{-\infty}^{+\infty}\left\{\begin{array}{l}
-\frac{1}{2} k s((t-L) \sin \alpha) e^{-a_{1} \lambda(x-t)}\left[\cos \left(a_{2} \lambda(x-t)\right)-\left(\frac{a_{1}^{2}-a_{2}^{2}}{2 a_{1} a_{2}}\right) \sin \left(a_{2} \lambda(x-t)\right)\right] d t \quad x-t>0 \\
\frac{1}{2} k s((t-L) \sin \alpha) e^{-a_{1} \lambda(t-x)}\left[\cos \left(a_{2} \lambda(t-x)\right)-\left(\frac{a_{1}^{2}-a_{2}{ }^{2}}{2 a_{1} a_{2}}\right) \sin \left(a_{2} \lambda(t-x)\right)\right] d t \quad x-t \leq 0
\end{array}\right\} d t .
\end{aligned}
$$

\section{B.1. Coefficients of the Matrix $\boldsymbol{k}_{i 5}$}

$$
\begin{aligned}
& k_{15}=-\frac{b_{i} a_{i-1}}{4 a_{1 i} a_{2 i} c_{i}{ }^{4} E_{i} I_{i}\left(a_{1 i}{ }^{2}+a_{2 i}{ }^{2}\right)}\left(\begin{array}{c}
-2 a_{1 i} a_{2 i}+2 a_{1 i} a_{2 i} F_{2 i} \\
+\left(a_{1 i}{ }^{2}-a_{2 i}{ }^{2}\right) F_{4 i}
\end{array}\right) \\
& +\frac{b_{i}\left(q_{i}-q_{i-1}\right)}{4 a_{1 i} a_{2 i} c_{i}{ }^{5} E_{i} I_{i} L_{3}\left(a_{1 i}{ }^{2}+a_{2 i}{ }^{2}\right)^{2}}\left(\begin{array}{c}
a_{2 i}\left(-3 a_{1 i}^{2}+a_{2 i}^{2}\right) F_{3 i} \\
+a_{1 i}\left(2 a_{2 i}\left(a_{1 i}^{2}+a_{2 i}^{2}\right) c_{i} x+\left(a_{1 i}{ }^{2}-3 a_{2 i}{ }^{2}\right) F_{1 i}\right)
\end{array}\right) \\
& k_{25}=\frac{b_{i} q_{i-1}\left(a_{2 i} F_{3 i}-a_{1 i} F_{1 i}\right)}{2 a_{1} a_{2}\left(a_{1}^{2}+a_{2}^{2}\right) c^{3} E_{i} I_{i}}+\frac{\left(b_{i}\left(q_{i}-q_{i-1}\right)\left(2 a_{1 i} a_{2 i}-2 a_{1 i} a_{2 i} F_{2 i}-\left(a_{1 i}{ }^{2}-a_{2 i}{ }^{2}\right) F_{4 i}\right)\right)}{\left(2 a_{1 i} a_{2 i}\left(a_{1 i}{ }^{2}+a_{2 i}{ }^{2}\right)^{2} c_{i}{ }^{4} E_{i} I_{i} x\right)} \\
& k_{35}=-\frac{b_{i} q_{i-1} F_{4 i}}{2 a_{1 i} a_{2 i} c_{i}^{2}}-\frac{b_{i}\left(q_{i}-q_{i-1}\right)\left(a_{2 i} F_{3 i}-a_{1 i} F_{1 i}\right)}{2 a_{1 i} a_{2 i} c_{i}^{3}\left(a_{1 i}^{2}+a_{2 i}^{2}\right) x}, \\
& k_{45}=-\frac{b_{i} q_{i-1}}{\left(a_{1 i}{ }^{2}+a_{2 i}{ }^{2}\right) c_{i}}\left(a_{1 i}\left(1+2 a_{1 i}{ }^{2} a_{2 i}^{2}-2 a_{2 i}{ }^{4}\right) F_{3 i}+a_{2 i}\left(1+2 a_{1 i}{ }^{2} a_{2 i}^{2}-2 a_{1 i}{ }^{4}\right) F_{1 i}\right) \\
& -\frac{b_{i}\left(q_{i}-q_{i-1}\right)}{\left(a_{1 i}^{2}+a_{2 i}{ }^{2}\right)^{2} c_{i}^{2} x}\left(\begin{array}{c}
\left(4 a_{1 i}{ }^{2} a_{2 i}{ }^{2}-1\right)\left(a_{1 i}{ }^{2}-a_{2 i}{ }^{2}\right)+\left(a_{2 i}{ }^{2}-4 a_{1 i}{ }^{4} a_{2 i}{ }^{2}+a_{1 i}{ }^{2}\left(-1+4 a_{2 i}{ }^{4}\right)\right) F_{2 i} \\
-2 a_{1 i} a_{2 i}\left(\left(a_{1 i}^{2}-a_{2 i}^{2}\right)^{2}-1\right) F_{4 i}
\end{array}\right) .
\end{aligned}
$$

\section{Conflicts of Interest}

The author declares that there are no conflicts of interest regarding the publication of this paper.

\section{Acknowledgments}

The author appreciates the help from the staff of Hangzhou and Hong Kong Tunnel Company Ltd. during instrumentation setup and data acquisition. This study is supported by the National Natural Science Foundation of China (no. 41702313).

\section{References}

[1] S. H. Kim, Model testing and analysis of interactions between tunnels in clay [Ph.D. Thesis], Department of Engineering Science, University of Oxford, Oxford, UK, 1996.
[2] H. Y. Liu, J. C. Small, J. P. Carter, and D. J. Williams, "Effects of tunnelling on existing support systems of perpendicularly passing tunnels," Computers and Geotechnics, vol. 36, no. 5, pp. 880-894, 2009.

[3] I. Yamaguchi, I. Yamazaki, and Y. Kiritani, "Study of ground-tunnel interactions of four shield tunnels driven in close proximity, in relation to design and construction of parallel shield tunnels," Tunnelling and Underground Space Technology, vol. 13, no. 3, pp. 289-304, 1998.

[4] T. I. Addenbrooke and D. M. Potts, "Twin tunnel interaction: surface and subsurface effects," International Journal of Geomechanics, vol. 1, no. 2, pp. 249-271, 2001.

[5] J. P. Kimmance, S. Lawrence, O. Hassan, and N. J. Purchase, "Observations of deformations created in existing tunnels by adjacent and cross cutting excavations," in Proceedings of Geotechnical Aspects of Underground Construction in Soft Ground, pp. 707-712, London, UK, July 1996.

[6] E. Leca and B. New, "Settlements induced by tunnelling in soft ground," Tunnelling and Underground Space Technology, vol. 22, no. 2, pp. 119-149, 2007. 
[7] S. M. Liao, J. H. Liu, R. L. Wang, and Z. M. Li, "Shield tunnelling and environment protection in Shanghai soft ground," Tunnelling and Underground Space Technology, vol. 24, no. 4, pp. 454-465, 2009.

[8] F. H. Chehade and I. Shahrour, "Numerical analysis of the interaction between twin-tunnels: influence of the relative position and construction procedure," Tunnelling and Underground Space Technology, vol. 23, no. 2, pp. 210-214, 2008.

[9] X. G. Li and D. J. Yuan, "Response of a double-decked metro tunnel to shield driving of twin closely underpasses tunnels," Tunnelling and Underground Space Technology, vol. 28, no. 1, pp. 18-30, 2012.

[10] T. E. Vorster, A. Klar, K. Soga, and R. J. Mair, "Estimating the effects of tunnelling on existing pipelines," Journal of Geotechnical and Geoenvironmental Engineering, vol. 131, no. 11, pp. 1399-1410, 2005.

[11] Z. G. Zhang, M. S. Huang, and W. D. Wang, "Evaluation of deformation response for adjacent tunnels due to soil unloading in excavation engineering," Tunnelling and Underground Space Technology, vol. 38, no. 3, pp. 244-253, 2013.

[12] A. P. S. Selvadurai, Elastic Analysis of Soil-Foundation Interaction, Elsevier Scientific Pub. Co., Amsterdam, Netherlands, 1979.

[13] N. Loganathan and H. G. Poulos, "Analytical prediction for tunnelling-induced ground movements in clays," Journal of Geotechnical and Geoenvironmental Engineering, vol. 124, no. 9, pp. 846-856, 1998.

[14] K. M. Lee, R. K. Rowe, and K. Y. Lo, "Subsidence owing to tunnelling. I. Estimating the gap parameter," Canadian Geotechnical Journal, vol. 29, no. 6, pp. 929-940, 1992.

[15] R. K. Rowe and K. M. Lee, "Subsidence owing to tunnelling. II. Evaluation of a prediction technique," Canadian Geotechnical Journal, vol. 29, no. 6, pp. 941-954, 1992.

[16] P. B. Attewell, J. Yeates, and A. R. Selby, Soil Movements Induced by Tunnelling and their Effects on Pipelines and Structures, Methuen Inc., New York, NY, USA, 1986.

[17] F. Ye, C. He, H. H. Zhu et al., "Analysis of longitudinal equivalent stiffness of shield tunnel considering lateral performance," Chinese Journal of Geotechnical Engineering, vol. 33, no. 12, pp. 1870-1876, 2011, in Chinese.

[18] P. R. Lancaster and D. Mitchell, "Problems in Bending of Bars and Plates [M]," Advanced Solid Mechanics, Macmillan, UK, 1980.

[19] L. Xu, "Study on vertical settlement of shield tunnel in soft soil," Ph.D. dissertation, Tongji University, Shanghai, China, 2005.

[20] M. Yang and X. Zhao, "An approach for a single pile in layered soil," Tongji University. Natural Science, vol. 20, no. 4, pp. 421-428, 1992, in Chinese. 


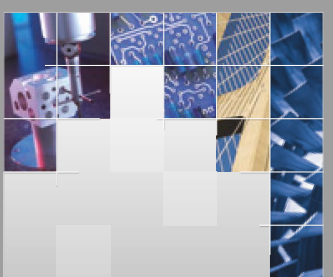

\section{Enfincering}
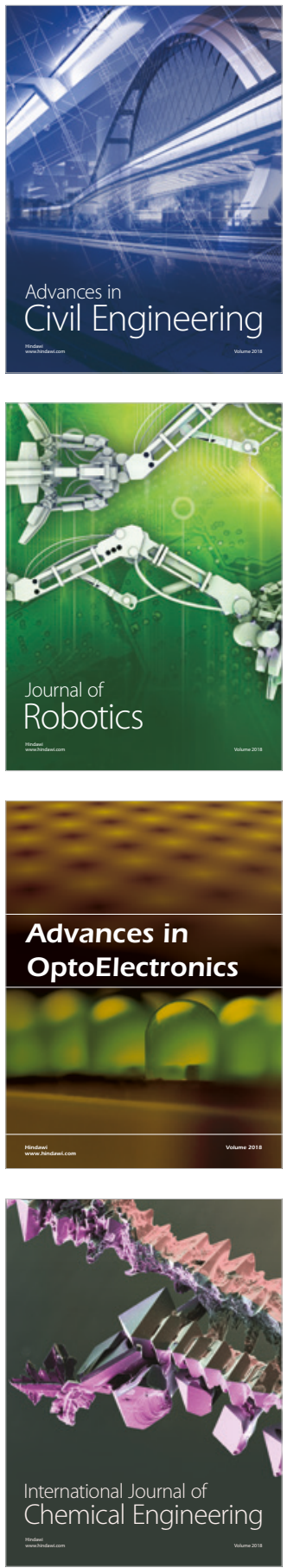

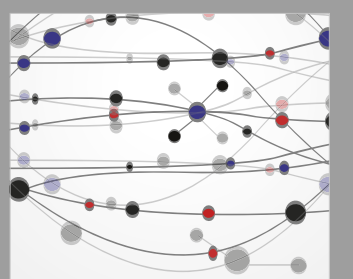

\section{Rotating \\ Machinery}

The Scientific World Journal

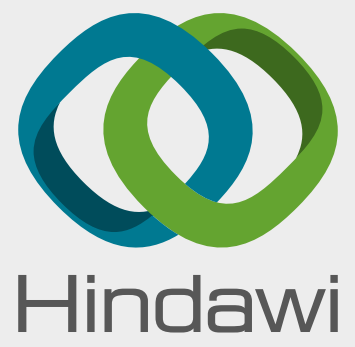

Submit your manuscripts at

www.hindawi.com
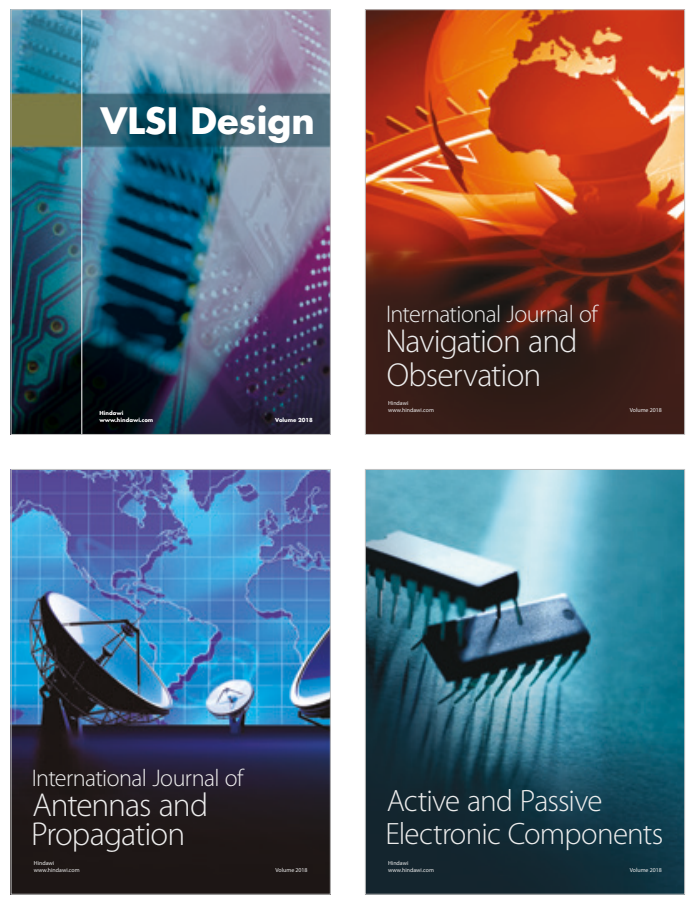
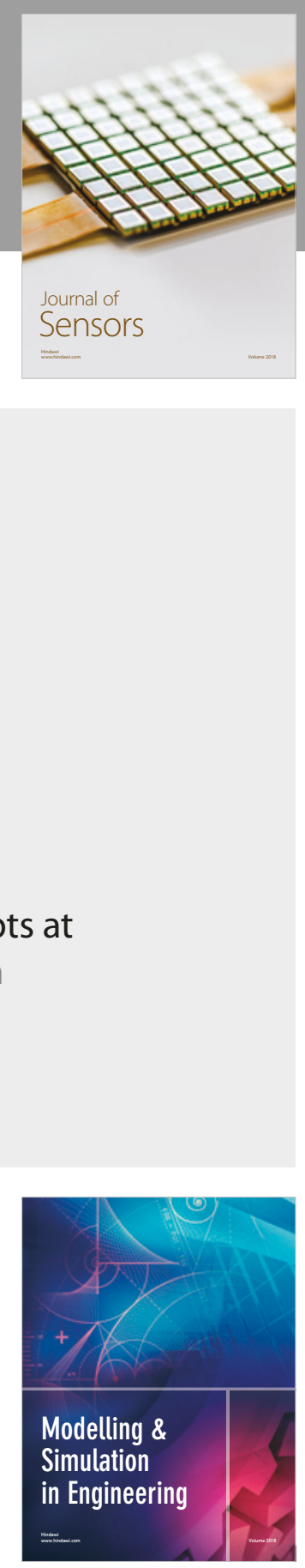

\section{Advances \\ Multimedia}
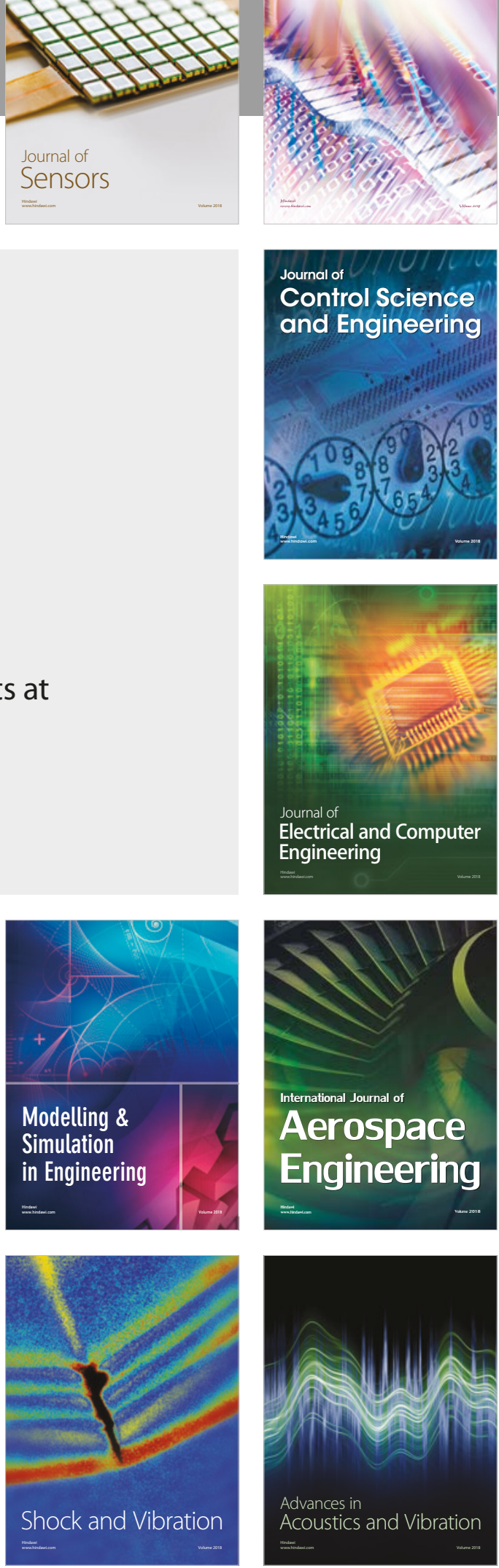